Johannes Renz*

\title{
Alt oder spät? (Teil 2)
}

Die Abfolge wa-Perfekt als Element der althebräischen Verbalsyntax im Kontext des nordwestsemitischen Verbalsystems. Eine Problemanzeige aus der Perspektive der nordwestsemitischen Epigraphik

DOI 10.1515/zaw-2016-0036

\section{Zweiter Hauptteil: Das Tempussystem der hebräischen Inschriften}

Stellt man der Tempusverwendung in den älteren außerhebräischen Sprachen Syrien-Palästinas nun in einem zweiten Hauptpunkt das Tempussystem der hebräischen Inschriften gegenüber, so fallen zwei komplementäre Beobachtungen auf: a) Wenn es um die Darstellung von Vorzeitigem oder Vergangenem geht, so überwiegt das einfache Perfekt bei weitem - mit deutlich über 90 Belegen. ${ }^{180}$ b) Dem stehen andererseits genau 3 Inschriften mit 6 Belegen für den Narrativ gegenüber ${ }^{181}$ - in der gesamten vorexilischen Zeit.

\subsection{Perfekt}

Charakeristisch für die Syntax der hebräischen Verwaltungsprosa ist ein Satzbau, der oftmals das Thema - auch ausdrücklich pendierend - voranstellt und dann als Rhema einfaches Perfekt mit weiteren Ergänzungen anschließt. Man vermeidet zusammenhängende Abfolgen. Dies ist natürlich auch der Gattung der Ostraka geschuldet, bei der mehrere Aufträge oder Aussagen zusammengefasst werden - man hat in diesem Zusammenhang auch von Bestellzettelsyntax ${ }^{182}$

180 Basis sind die in Anm. 2 genannten Inschriften.

181 Belege unten Kap. 3.2.2. Vgl. auch Schüle, Syntax, 163 und ff.

182 Schüle, Syntax, 154.

*Kontakt: Johannes Renz, Theologische Fakultät der Humboldt-Universität zu Berlin, Burgstraße 26, 10178 Berlin, johannesrenz@t-online.de 
gesprochen. Aber auch darüber hinaus neigt man dazu, immer erst die neue Thematik einzuführen und von dort aus dann mit Perfekt zu berichten.

Auffälligerweise fällt die Siloah-Inschrift (Jer[8]:3) ${ }^{183}$ aus dem ausgehenden 8. Jahrhundert in dieselbe Kategorie. Sie schildert die Vorgänge beim Tunnelbau kurz vor dem Durchbruch und hätte von der Gattung und Thematik her durchaus Anlass zur Verwendung von Narrativen gegeben. Allein die Übersicht zeigt den ständigen Neueinsatz durch Temporalbestimmungen und Nebensätze. Es gibt nur einen einzigen Narrativ ( $\underline{\underline{\text { doppelt }}}$ unterstrichen, neben Perfekt und gliedernden Tempusadverbien).

[Dies (?)] war der Tunneldurchbruch, und dies waren die Umstände des Tunneldurchbruchs:

בעוד מْנْ[יפם] הْחْצْבْםْ אْתْ 2הגרזן אש אל רעו ובעוד שלש אמת להנקْ

נשמ]

כי הית זדה בצר מימן וֹ[משמ]אל :
Als die Steinhauer noch die Hacke schwangen ... und als noch 3 Ellen zu durchschlagen waren, da wurde die Stimme eines jeden ... gehört, denn es war ein Spalt im Fels von Süden und von Norden.

ובים הינקבה

Und am Tag des Tunneldurchbruchs schlugen die Steinhauer ... und da floss das Wasser von der Quelle zum Teich ...
הכו החצבם אש לקרת רעו גרזן על [ג]רזן וילכו 5המים מן המוצא אל אל הברכה במאת גרון על וֹאלף אמה
Und 100 Ellen war die Höhe des

ומ[א]6ת אמה היה גבה הצר על ראש החצבם ומאת Felsen ...

Man erzählt offenbar nicht in der Form, dass man einmal zu Beginn durch Perfekt oder Tempusangabe den Fokus vom Referenzpunkt des Sprechenden in die Vergangenheit setzt und von diesem Punkt an dann weitererzählt - mit Progresstem-

183 Zur Lit. vgl. HAE I, Nr. Jer(8):3; HI, 499-506 (Silm 1); EP, 19-25; Weippert, Textbuch, $328 \mathrm{f}$. (Nr. 180); Karl Jaroš, Zeugen auf Stein und Ton. Inschriften des Heiligen Landes und seiner Nachbarregionen aus vier Jahrtausenden (Wiesbaden: Harrassowitz, 2014), 138-142. 
pus Narrativ, unterbrochen durch Umstandssätze und dergleichen -, sondern so, dass man immer wieder vom Referenzpunkt des Sprechenden aus ansetzt und von der virtuellen Gegenwart des Redenden aus einzelne Fakten der Vergangenheit quasi konstatierend aneinanderreiht. ${ }^{184}$

Hier könnte sich neben der $\mathrm{zu}$ erwartenden Abfolge wa-x-qatal unter Umständen auch einfaches wa-qatal einfügen, nicht im Sinne eines Progress, sondern zur Aufzählung einzelner Fakten, auch wenn diese insgesamt wie im Falle der Siloah-Inschrift der Sache nach in einem zeitlich-logischen Zusammenhang stehen.

\subsection{Narrativ}

\subsubsection{Narrativ und Perfekt in den außerhebräischen Inschriften}

Anders formulieren die erhaltenen moabitischen Königsinschriften sowie die altaramäische Inschrift von T. Dān: Das Grundgerüst dieser eher literarischen Inschriften stellt - auch vom Umfang her - eine Serie von Verbalsätzen mit waKurz-Imperfekt, ${ }^{185}$ den biblisch-hebräischen Narrativen entsprechend, dar.

1) Die moabitische Meša'-Inschrift ${ }^{186}$ ist inhaltlich-thematisch recht gut strukturiert. ${ }^{187}$ Trotzdem werden solche Grenzen keineswegs immer durch die im Biblisch-Hebräischen übliche Unterbrechung der Narrativkette durch einführende Nominalsätze oder besonders durch Verbalsätze mit einfachem Tempus

184 Damit kann aber nicht davon die Rede sein, dass ältere und früher allgemein gebräuchliche Narrative bereits hier langsam außer Gebrauch gekommen wären (so etwa Garr, Geography, 185 f.; Smith, Origins, 20; vgl. Daniel C. Fredericks, Qoheleth's Language. Re-evaluating its Nature and Date, ANETS 3 [Lewiston, NY / Queenston, Ontario: Mellen, 1988], 38 f.). Dafür sind die dafür herangezogenen inschriftlichen Belege für einfaches Perf. zu alt (es geht nicht nur um das 6. Jh. v. Chr.) und die Masse der biblisch-hebr. Narrativbelege deutlich später - auch bei konservativer Datierung biblischer Texte. Zielführender dürfte die Beobachtung sein, dass unterschiedliche Sprachverwendungen und Sprachmilieus auch unterschiedliche Formen des Verbgebrauchs hervorbringen, die sich zeitlich überlappen können; dazu unten Kap. 5.4.

185 Vgl. auch die ältere Zusammenstellung bei Smith, Origins, 17-21.

186 KAI Nr. 181; Kent B. Jackson, »The Language of the Mesha' Inscription, « in Studies in the Mesha Inscription and Moab, Hg. Andrew Dearman (Atlanta: Scholars Press, 1989): 96-130; EP, 389-418; Weippert, Textbuch, 242-248; Erasmus Gaß, Die Moabiter - Geschichte und Kultur eines ostjordanischen Volkes im 1. Jahrtausend v. Chr. (Wiesbaden: Harrassowitz, 2009). - Zum Text auch: $K A I^{5}$ I Nr. 181.

187 Neben älteren Strukturierungen bei Francis I. Anderson, »Moabite Syntax, « OrNS 35 (1966): 81-120, 82-88; 114-116; Pierre Auffret, »Essai sur la structure littéraire de la stèle de Mésha, «UF 12 (1980): 109-124, 110 ff. und KAI II, 168 f.; besonders Schüle, Syntax, 164-172; Weippert, Textbuch, 243 f. und Gaß, Moabiter, 50-52. 
und der Satzteilfolge wa-x-qatal - neben der Realisierung vorzeitiger Umstandssätze eine der Paradeanwendungen von wa-x-qatal bei individuellen Sachverhalten der Vergangenheit - gekennzeichnet. ${ }^{188}$ Man erzählt durchaus über thematische Grenzen hinweg mit Narrativen weiter. ${ }^{189}$

a) Zu Beginn des Abschnitts über Madeba (Z. 7-10) in Z. 7: וירש עמרי את כל ארץ מהדבא וund Omri hatte das ganze Land von Madeba in Besitz genommen «; ${ }^{190}$ danach - streng genommen mit וישבה כמש וaber Kemosch brachte es zurück« - beginnt die eigentliche, ebenfalls durch Narrative realisierte Erzählkette. - b) Zu Beginn des Abschnitts über Nebo (Z. 14-18) in Z. 14: ויאמר לי כמשda sagte Kemosch zu mir ...«.

Wie von anderer Seite längst bemerkt, konzentriert sich das nicht zusammengesetzte Tempus (wa-x-)Perfekt auf von der Erzählebene aus betrachtet Vorzeitiges, auf Hintergrundinformationen, auch auf Stativisches, das dann zur Einleitung eines neuen Abschnitts dienen kann, aber nicht dienen muss.

a) Innerhalb der Einleitung (Z. 1-4) stellt nach der notwendigen Selbstvorstellungsfor-

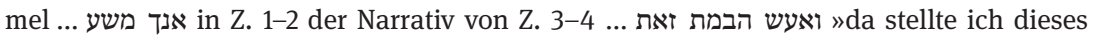
Höhenheiligtum ... her« die eigentliche Aussage dar, die die Aufstellung der Stele und der Inschrift begründet. Eingeführt wird der Passus Z. 2-4 aber durch zwei parallel gesetzte Perfekta ... אבי מלך על מאב ... || ואנך מלכתי אחר אבי "mein Vater war König über Moab ... || und ich wurde König nach meinem Vater«. Deutlich vorzeitig - auch gegenüber dem Berichteten, nicht nur gegenüber der Erzählerebene - werden die Voraussetzungen/Hintergründe zum Baubericht, der Hauptaussage, genannt. - b) Der allgemeine Abschnitt über Moab עמרי מלך (Z.4-7), dessen Hauptgerüst Narrative bilden, wird durch vorzeitig-stativisches ישראל (Omri war König von Israel ...« eröffnet, das die Voraussetzungen für das Folgende nennt. - Ganz analog benennen die einleitenden Perf. - von den letztlich Zustände bezeichnenden Verben מלד und ישב zu Beginn von drei weiteren Abschnitten allgemeine und zeitlich zurückliegende Voraussetzungen, während der eigentliche Bericht aus Narrativen erst danach beginnt: c) Abschnitt über Yahaș (Z.18-21) in Z.18 f.: ומלך ישראל בנה את יהץ וund der König von Israel hatte Yahaș (aus)gebaut«. - d) Abschnitt über Hauronen (Z. 31 ff.) in Z. 31 mit Casus pendens: וחורנן ישב בה בת [ד] וד וund was Ḥauronen angeht, so wohnte (bislang) >Haus-David` (Juda) darin ....". - e) Abschnitt über 'Ațarōt (Z. 10-14) in Z. 10, verstärkt durch וund die Männer von Gad wohnten im Land 'Ațarōt seit jeher«.

188 Vgl. Gaß, Moabiter, $51 \mathrm{f}$.

189 Moderne Übersetzungen versuchen hier oft, so zu übersetzen, als läge auch syntaktisch eine Unterbrechung der Narrativkette vor.

190 Ein wa-Perf. mit folgendem Subj. wäre im Text sonst nicht belegt, entspräche aber der Struktur von $\operatorname{Arad(3):3~Z.~} 2$ f. (dazu unten Kap. 4.1.2.1). Die übrigen Verwendungen des Perf. im Text lassen eher die Abfolge (wa)-x-qatal erwarten; siehe dazu im Folgenden. 
Das biblisch-hebräische Verfahren, am Eingang einer Erzählreihe bereits das erste Element der Vorgangsreihe - und nicht nur deren Hintergrund - mit (wa-) $x$-qatal zu formulieren und erst dann den weiteren Progress mit Narrativen anzuschließen, kommt außerbiblisch nicht zur Anwendung. ${ }^{191}$ Damit entspricht die Tempuswahl durchaus noch dem älteren Schema, welches das Kurz-Imperfekt zumeist durch $w a$ - erweitert - einfach als reguläres Erzähltempus kennt, offenbar ohne weitere Differenzierungen vorzunehmen. Die Tempuswahl dient der Verzeitung und parallel der Reliefbildung - Vorder- / Hintergrund. ${ }^{192}$

Daneben und passend zum vorher Gesagten benennt einfaches Perfekt Vorzeitiges in Nebensätzen: Z. 4: כי השעני ... וכי הראני כdenn er hat mich errettet ...

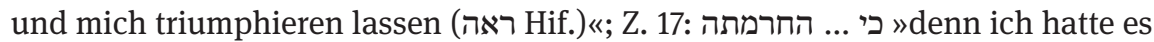
durch Bann ... geweiht «. ${ }^{193}$

Zuletzt kann (wa-x-)Perfekt auch stilistisch zur Realisierung chiastischer Strukturen verwendet werden und bezeichnet als an zweiter Stelle gewähltes Tempus gleichzeitig auch den Abschluss einer Aussage: Innerhalb des Abschnitts

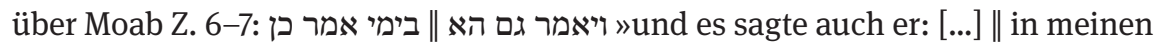

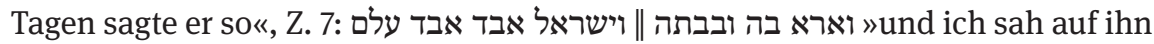
und auf sein Haus (herab) || und Israel ging gewiss unter für alle Zeit«. ${ }^{194}$ Innerhalb des Abschnitts über 'Ațārōt Z. 11-12: ואחזה ואהרג את כל העם || הקר הית לכמש ולמאב וund ich nahm sie (die Stadt) ein und erschlug das ganze Volk || die Stadt aber gehörte (von nun an) Kemosch und Moab« (durch היה verzeiteter Nominalsatz).

Für alles gäbe es, wie oben gezeigt, ugaritische Parallelen. ${ }^{195}$

Ist kein Progress gemeint, so werden konstatierend eigene Taten im Laufe der Herrschaftszeit durch (ו) (ו) (ו) (und) ich baute..." usw. eingeführt, also einfaches Perfekt, so überwiegend in den Abschnitten Z. 21-31. ${ }^{196}$ Bei zeitlich voneinander unabhängigen Geschehnissen, die nicht in einem Ereigniszusammenhang stehen, setzt man demnach immer wieder von neuem in der Gegen-

191 Wenn bereits das erste Element eines Abschnitts Teil der Erzählkette ist, wird offenbar sofort mit Narr. eingesetzt (s. o. zu Z. ויאמר 14 ויאמי).

192 Dies wird auch von Schüle, Syntax, 170-172 herausgestellt - die dort damit implizierte Deutung des Perf. als atemporaler Stativ zur Beschreibung von Zuständen erscheint im Kontext aber nicht notwendig.

193 Analog findet sich in Z. 5-6 für Durativisches das einfache Lang-Ipf. ... כי יאנף כמש denn Kemosch zürnte ...«.

194 Etwas abweichend Schüle, Syntax, 170.

195 Dazu oben Kap. 2.2.1.2.

196 Ähnlich auch im 3. Hauptteil der altaramäischen Zakkūr-Inschrift; dazu oben Kap. 3.2.3 Abschn. 2. 
wart des Berichtenden an, um dann mit vorzeitigem Perfekt in die Erzählzeit zu wechseln. ${ }^{197}$

2) In ähnlicher Weise kennt auch ein aus dem Antikenhandel stammendes Fragment einer moabitischen Königsinschrift aus dem zweiten Drittel des 8. Jahrhunderts ${ }^{198}$ den Wechsel von Narrativen und der Abfolge wa-x-qatal. Wie die Meša'-Stele blickt auch diese Inschrift auf vergangene Taten des Königs zurück hier vor allem die Gefangennahme und Plünderung von Ammonitern sowie Baumaßnahmen, teilweise unter Heranziehung der Kriegsgefangenen.

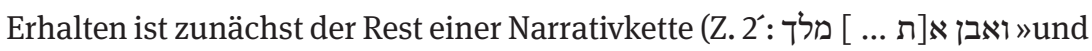
ich baute [...] des Königs«; wahrscheinlich sind dem weitere Narrative vorausgegangen).

Dem folgen weitere Einzelmaßnahmen, die in sich selbstständig durch $w a-x$ -

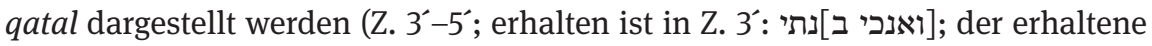
Rest lässt vom Satzbau her ebenfalls wa-Perfekta erwarten).

Im Grunde einen Neueinsatz stellt der folgende Narrativ in Z. 5 f. dar: ו.... וירא בניעמן כי חלה בכל (als kah Ammon (allektiver Singular konstruiert), dass es krank / schwach war in allen [...]«. Gleichzeitig könnte auch die Folge aus allem Vorangegangenen mitgemeint sein.

Der Narrativ dient, soweit erkennbar, als eigentliches Erzähltempus; das vorzeitige Perfekt wird zur parallelen Beschreibung mehrerer Einzelmaßnahmen verwendet - die vielleicht dann wieder die Voraussetzung für das Folgegeschehen bilden (Z. $5 \mathrm{ff}$.).

3) Soweit die sehr fragmentarische aramäische Inschrift von T. $D \bar{a} n^{199}$ überhaupt rekonstruierbar ist, ist sie - ganz analog zur Meša'-Inschrift - von Narrativketten dominiert, die im erhaltenen Text an zwei Stellen durch einfache Präformativkonjugationen ${ }^{200}$ und an einer weiteren Stelle durch wa-Perfekt ${ }^{201}$ unterbrochen sind. Auffällig ist, dass wie in der Meša'-Stele der Narrativ offenbar wie in den älteren Sprachen allgemeines Erzähltempus ist: Weitere Untergliederungen können, müssen aber nicht syntaktisch angezeigt werden. In Z. 3 ויעל מלך ישראל mit - meginnt - einfach durch einen neuen Narrativ eingeführt

197 Vgl. Smith, Origins, $18 \mathrm{f}$.

198 Shmuel Ahituv, »A New Moabite Inscription, «Israel Museum Studies in Archaeology 2 (2003): 3-10; André Lemaire, »Note d'information. Essai d'interprétation historique d'une nouvelle inscription monumentale moabite, « CRAIBL 149 (2005): 95-108; EP, 419-423; Gaß, Moabiter, 76-83. 199 Abraham Biran und Joseph Naveh, »An Aramaic Stele Fragment from Tel Dan, «IEJ 43 (1993): 81-98; dies., »The Tel Dan Inscription: A New Fragment, «IEJ 45 (1995): 1-18; George Athas, The Tel Dan Inscription, JSOT.SS 360 (Sheffield: Sheffield Academic Press, 2003); EP, 464-473; Weippert, Textbuch Nr. 116. Weitere Lit. s. u. Kap. 4.2.3.2.

200 Z. 2: [...]יסיר und Z. 3: יהך,

201 Z. 7-9 zweimal וקתלת; dazu unten Kap. 4.2.3.2. 
עund der König von Israel war vormals in das Land meines Vaters hinaufgezogen « ${ }^{202}$ erkennbar ein neuer Abschnitt, der die Voraussetzung für die folgende erfolgreiche Kriegsführung bietet; der vorhergehende Abschnitt dürfte mit dem Tod des königlichen Vaters zu Ende gekommen sein. In Z. $11 \mathrm{f}$. könnte dagegen die Voraussetzung für eine folgende Erzählkette durch stativisches und vorzeitiges wa-x-qatal zum Ausdruck gebracht worden sein: [ויהוא מ]לך על יש[ראל] »und Jehu war König über Israel (geworden)«.

Die kurz nach der Publikation der Inschrift vor allem von Takamitsu Muraoka ausgelöste Diskussion, ob wyqtl - hier und in anderen nicht-hebräischen / nicht-kanaanäischen Texten - überhaupt als Narrativ im biblisch-hebräischen Sinne zu verstehen wäre, ${ }^{203}$ geht von der Annahme aus, dass sich wa-conversivum / consecutivum überhaupt - morphologisch wie funktional - von wa-copulativum unterscheide. ${ }^{204}$ Unbestritten blieb dabei die präteritale Übersetzung des Kurz-Ipf. - sowohl separat (Z. 2 und 2) als auch mit vorangestellter Konj. wa- -, so dass sich inhaltlich im Grunde nichts änderte. ${ }^{205}$ wyqtl ist damit tatsächlich nichts anderes als ugaritisch wyqtl, amarna-kanaanäisch $u$-Kurz-Ipf. usw. Gleich wie man masoretisches wayyiqtōl und damit wa-consecutivum erklärt, ein genetischer Zusammenhang mit vorhebräischem wyqtl muss immer vorausgesetzt werden.

Es bleibt die Problematik, dass die masoretische Unterscheidung von wa-consecutivum mit Verdopplung des Folgekonsonanten und $w^{e}$-copulativum selbst in den griechischen Transkriptionen der Secunda des Origenes oder der samaritanischen Aussprachetradition noch nicht, in den vortiberiensischen Punktationen nur sporadisch nachweisbar ist. ${ }^{206}$ Auf die hier zu untersuchenden Texte der althebr. Epigraphik angewandt bedeutet dies, dass ohne Kenntnis der etwa eineinhalb Jahrtausende (!) späteren ältesten Handschriften der tiberiensischen Schule niemand auf den Gedanken käme, althebräisch progressiv-erzählendes wyqtl der inschriftlichen Belege von form- und funktionsgleichem wyqtl des Ugaritischen, Amarna-Kanaanäischen, Moabitischen oder Altaramäischen zu unterscheiden.

Es kann für die vorliegende Untersuchung auch unberücksichtigt bleiben, ob wyqtl zusätzlich zum individuellen Sachverhalt der Vergangenheit auch den Progress bezeichnet ${ }^{207}$ und ob dieser primär durch die Konj. $w a$ - bedingt oder bereits im Kurz-Ipf. alleine ${ }^{208}$ angelegt ist. In jedem Falle stellt Kurz-Ipf. mit Konj. wa- das Erzählgerüst dar.

202 Weippert, Textbuch Nr. 116: »da war ... damals in das Land ... gekommen «; EP, 468: »and the king ... entered previously ...«.

203 Den Ausgang bildete Takamitsu Muraoka, »Linguistic Notes on the Aramaic Inscription from Tel Dan, «IEJ 45 (1995): 19-21, 19 f. Vgl. dazu besonders Josef Tropper, »Aramäisches wyqtl und hebräisches wayyiqtol, « UF 28 (1996): 633-645 mit älterer Lit. sowie den Diskussionsüberblick bei Athas, Inscription, $200 \mathrm{ff}$.

204 Ein Überblick über die Diskussion findet sich bei Waltke und O’Connor, Syntax, § 29; vgl. Gzella, Tempus, $322 \mathrm{f}$.

205 Vgl. die Übersetzungen Muraokas (ebd. 19): Z. וישכב 2 וand he lay« usw.

206 Dazu u. a. Müller, »Imperfectum consecutivum«: 146-148.

$207 \mathrm{Zu}$ dieser Definition bereits Walter Gross, Verbform und Funktion. wayyiqtol für die Gegenwart?, ATSAT 1 (St. Ottilien: EOS, 1976), 6, zur Funktion auch 163-166.

208 So bes. Kottsieper, »Aspekte«: 55-76, speziell 70-72. 
Konsequent weiter geht George Athas, ${ }^{209}$ der in Weiterführung von Muraoka dann nach $w a-$ copulativum auch Lang-Ipf. und damit futurische Bedeutung annimmt - freilich auf Kosten des Inhalts und der Gattung einer typischen Monumentalinschrift.

Man wird hier also insgesamt einen Reflex literarischer Prosa vorfinden, während die hebräischen Inschriften anscheinend einer anderen Sprachebene zuzurechnen sind.

Die beiden weiteren Belege für den Narrativ außerhalb des Hebräischen - die aramäischen Verputzinschriften von T. Dēr 'Allā und die aramäische Inschrift von $\bar{A} f i s$ - kennen eingesprengte Passagen von Narrativen, ohne von diesen dominiert zu sein. Das Ganze ähnelt ein wenig dem System der hebräischen Inschriften. ${ }^{210}$

\subsubsection{Der Narrativ in den hebräischen Inschriften}

Der Narrativ selbst ist in den Texten der hebräischen Inschriften auf 6 Formen in 4 Belegen aus 3 Inschriften konzentriert: ${ }^{211}$

1.) Der Narrativ erscheint zunächst als Einzelbeleg in zwei Inschriften:

- Lachisch-Ostrakon Nr. 4: Lak(6):1.4 Z. 6 f. ${ }^{212}$

וסמכיהו לקחה שמעיהו

זיעלהו העירה

- Siloah-Inschrift: Jer(8):3, $5 \mathrm{f}^{213}$

ובים הנקבה הכו החצבם ....

וילכו המים מן המוצא אל הברכה und was $S^{e}$ makyāhū angeht, so hat ihn Šema'yāhū genommen und ihn in die Stadt hinaufgeführt

und am Tage des Tunneldurchbruchs schlugen die Steinhauer ....

Da lief das Wasser von der Quelle zum Teich

In jedem Fall wird ein einfaches Perfekt fortgeführt. In Lachisch-Ostrakon Nr. 4 nahm ein gewisser Šema yahu eine andere Person und führte diese dann hinauf in die Stadt. Die Siloah-Inschrift berichtet in Z. 3 f. vom Tunneldurchbruch im

209 Athas, Inscription, 204 ff. Die Begründung ist die geläufige, dass aus Gründen der Sprachökonomie nicht zwei Morpheme - Präteritum / Kurz-Ipf. / PKK und Perfekt / AK - dieselbe Bedeutung gehabt haben dürfen.

210 Vgl. auch unten Kap. 4.2.3.2.

211 Vgl. auch die Zusammenstellung bei Gogel, Grammar, 262.

212 HAE I, 419-422 (Lak[6]:1.4); HI, 314-319, bes. 315; EP, 69-76, bes. 70; Weippert, Textbuch, 423. 213 Zur Literatur s. o. Kap. 3.1. Weippert, Textbuch, 328 f. z. St.: »da floss das Wasser ...«. EP, $22 \mathrm{f}$. differenziert nicht weiter: »... the hewers struck ... and the waters flowed ...«. 
Perfekt und gibt mit Narrativ וילכו die Folge an: Man möchte übersetzen: »so dass das Wasser von der Quelle zum Teich floss«.

Der Narrativ hat ausgeprägten Progresscharakter in sonst mit Perfekta formulierten Texten. In allen Fällen stellen die Narrative in keiner Weise das Gerüst eines Textes dar; vielmehr erscheinen sie gezielt an bestimmten Stellen eingesetzt, um die unmittelbare Folge aus dem vorher Gesagten darzustellen - das so Ausgedrückte bildet eine logische Einheit mit dem Vorhergehenden.

2.) Anders als die beiden vorgenannten Belege, deren vereinzelte Narrative nur die unmittelbare Folge aus dem vorher Gesagten benennen, kennt die Petition eines Erntearbeiters aus Meșad Hašabyāhu ${ }^{214}$ vom Ende des 7. Jahrhunderts zwei kürzere Narrativketten. In die Gesamtargumentation, die als Rede gestaltet naturgemäß individuelle Sachverhalte der Gegenwart, auslösende Modi, Bedingungssätze etc. enthält, wurde dem Charakter eines Beschwerdebriefs entsprechend, der ja auf spezielle Vorkommnisse und damit individuelle Sachverhalte der Vergangenheit reagiert, an zwei Stellen jeweils eine kurze, durch Narrative ausgedrückte Sequenz von Ereignissen, auf deren unmittelbare Abfolge es in der Argumentation ankommt, eingebettet.

a) Der Hauptvorwurf in Z. 6-9 enthält den in Narrativen formulierten Bericht \וda kam Hauša'yāhū ... und nahm das Kleid deines Dieners«. Konzentrisch eingerahmt wird dieser Kurzbericht durch zwei aussageidentische Temporalsätze, die, mit Perfekt formuliert, den vorangegangenen, der Rechtfertigung dienenden ersten Bericht ${ }^{215}$ aufnehmen:

- $\operatorname{MHas}(7): 12.6-9$

כאשר כל [ע]בדך את קצר/ה) ויבא הושעיהו בן שבי
ויקח את בגד עבדך

כאשר כלת את קצרי

\author{
Gerade als dein Diener seine ${ }^{216}$ Ernte \\ abmaß ..., \\ da kam Hauša 'yāhū ... \\ und nahm das Kleid deines \\ Dieners, \\ gerade als ich meine Ernte abmaß.
}

Ähnlich der Konstruktion der Meša'-Inschrift stellt das eröffnende Perfekt nicht den ersten Vorgang der Erzählung dar, sondern benennt die Voraussetzungen des Vorgangs - syntaktisch deutlich durch die Formulierung als Nebensatz und die konzentrische Wiederaufnahme am Ende des Abschnitts.

214 Lit. bei HAE I, 315-329 (MHas[7]:1) und HI, 358-370 (MHsh 1). Dazu bes. CoS 3, 77 f. (Pardee); EP, 156-163; Weippert, Textbuch, 370-372 Nr. 225. Weitere Lit. unten Kap. 4.1.3.

215 Siehe Abschn. b.

216 Zur üblichen Ergänzung des Pron.-Suff. s. HAE I, 326. 
b) Nochmals erscheint eine Narrativkette - vor dem Hauptvorwurf - und beinhaltet als Rechtfertigung den täglichen Arbeitsablauf des Bittstellers, der beansprucht, alles richtig und vollständig gemacht zu haben: Hier kommt es auf die narrative Abfolge in der Argumentation an.

- $\operatorname{MHas}(7): 1 \mathrm{Z} .2-6$

\begin{tabular}{|c|c|}
\hline היה עבדך בחצר אסם & Als dein Diener in $\langle\mathrm{ON}\rangle$ war, \\
\hline ויקצר עבדך & da erntete dein Diener \\
\hline ויכל & und maß ab \\
\hline ואסם .... & und häufte in den Speicher ... \\
\hline
\end{tabular}

Das vorausgehende einfache Perfekt ist auch hier nicht Teil der Erzählsequenz, sondern benennt als durch היה verzeiteter Nominalsatz die Voraussetzung der eigentlichen Erzählung - auch hier wiederum Meša' entsprechend.

Narrative werden offenbar gezielt eingesetzt zur Darstellung von Handlungssequenzen. Einleitendes Perfekt benennt die Voraussetzungen, nicht das erste Element der Erzählkette.

\section{היה T.3 Tempusmarker - das Verbum}

Ins Bild eines nicht im vollen Umfang einer Normgrammatik der hebräischen Bibel passenden Systems fügt sich auch die Tatsache, dass die Tempusmarker

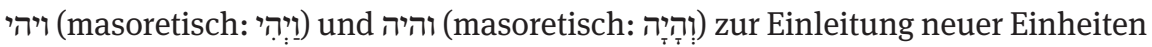
und damit zu Beginn eines Satzes nicht nachweisbar sind. ${ }^{217}$ היה: וריה wird - vielleicht häufiger als in der hebräischen Bibel, aber in Übereinstimmung z. B. mit dem phönizischen Befund - zur einfachen Verzeitung von Nominalsätzen gebraucht:

- Meșad Ḥašabyāhū Petition: MHas(7):1 Z. 2 ff. ${ }^{218}$

$$
\text { Dein Diener ist Schnitter. }
$$

Als dein Diener in $\langle\mathrm{ON}\rangle$ war,

da erntete dein Diener und maß ab

und häufte in den Speicher ...

217 Schüle, Syntax, 182 (ff.). Bereits Dennis Pardee, »Letters from Tel Arad, « UF 10 (1978): 289336, 311.

218 Zur Lit. s. o. Kap. 3.2.2. - Die Funktion von היה ist dieselbe, wenn man קצר als Prädikat / Rhema zum folgenden Satz zieht: »dein Diener erntete in $\langle\mathrm{ON}\rangle$ « (neuerdings etwa $E P, 159$ ). 
- Siloah-Inschrift: Jer(8): $3^{219}$

Z. 1

וזה היה דבר הנקבה

בי הית זדה בצר מימן וֹ[משמ] אל

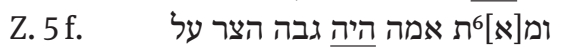
ראש החצבם und dies waren die Umstände des Tunneldurchbruchs: denn es war ein Spalt ... Und 100 Ellen war die Höhe des Felsen ...

- Zudem leitet Perf. cons. והיה nach einer Tempusangabe in Ostrakon Nr. 5 aus Horvat 'Uzzā / H. Ǵazze (Gaz[7]:5) einen zukünftigen Zustand ein, der durch Nominalsatz zum Ausdruck gebracht wurde. ${ }^{220}$

In der Siloah-Inschrift wie auch in der Petition von Meșad Hašabyāhū werden mehrfach generelle Sachverhalte durch einfaches Perfekt von היה - auch in Erststellung - verzeitet. Die wenigen weiteren Belege der Perfekt-Form היה stehen in stark fragmentarischem Kontext. ${ }^{221}$

Diese Verzeitung meist vergangener Zustände durch היה deckt sich im übrigen weitgehend mit der Verwendung des korrelierenden Verbs כון im Phönizischen.

\section{Dritter Hauptteil: wa-Perfekt in den hebräischen Inschriften}

Wendet man sich nun im dritten Hauptteil den konkreten inschriftlich-hebräischen Belegen $\mathrm{zu}^{222}$ so soll es zunächst um die Fälle gehen, bei denen 1) waPerfekt nach nicht-auslösenden Verbformen oder sogar gleich zu Beginn eines Satzes bzw. einer logischen Untereinheit des Textes begegnet - neben 2) den dem biblisch-hebräischen Perf. cons. entsprechenden Verwendungsweisen des waPerfekts -, die im Anschluss angesprochen werden sollen.

\section{1 wa-Perfekt nach nicht-auslösenden Modi}

\subsection{1 wa-Perfekt im Nachsatz von Bedingungssätzen}

Konventionell im Sinne anderer nordwestsemitischer Sprachen einschließlich des Ugaritischen oder Amarna-Kanaanäischen ist die Verwendung von wa-Per-

219 Zur Lit. s. o. Kap. 3.1.

220 Dazu unten Kap. 4.2.2 Abschn. b.

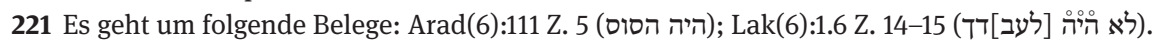
Zudem findet sich ein mit wa-copulativum angereihter Jussiv in KAgr(9):9 Z. 8.

222 Vgl. auch die ältere Zusammenstellung der Konj. wa- mit unterschiedlichen Verbalformen bei Gogel, Grammar, 261-268. 
fekt im Nachsatz von Bedingungssätzen in zwei fragmentarischen Inschriften des ausgehenden 9. und mittleren 8. Jahrhunderts.

Eine der Kruginschriften aus Kuntillet 'Ağrūd nennt entweder rückblickend oder generell feststellend die letztlich auf Jahwe zurückgehende Bitterfüllung:

- KAgr(9):10 Z. 2-3 $3^{223}$

: ואם פתה So gab / gibt ihm Jahwe nach seinem Wunsch (Herzen)

Im Nachsatz des zweiten Stichos folgt auf den Bedingungssatz »und wenn er eindringlich bat / bittet « der Nachsatz mit wa-Perfekt ונתן »so gab / gibt ihm Jahwe nach seinem Wunsch «. ${ }^{224}$ Die Abfolge wa-Perfekt erscheint bereits im älteren und zeitgleichen Kanaanäischen zur Einleitung der Apodosis, ${ }^{225}$ auch nach Perfekt in der Protasis. 226

Die sehr fragmentarische Elfenbeininschrift aus Nimrūd, letztlich aus Samaria stammend, kennt die Verbalform ומחו וund sie werden / man wird auslöschen «, vielleicht im strafenden Nachsatz eines Bedingungssatzes, der das feindliche Herankommen von irgendjemandem - vom Großkönig bis zum einfachen Mann - beschreibt.

223 Die Inschrift wurde zunächst ohne Kontext nur in Transkription veröffentlicht. Zur älteren Lit. vgl. HAE I, 63 f. (KAgr[9]:10); HI, 295 (KAjr 20); CoS 2, 172 Nr. 2.47B (McCarter); Ziony Zevit, The Religions of Ancient Israel. A Synthesis of Parallactic Approaches (London, New York: Continuum, 2001): 398-400; EP, 318 f.; Johannes Renz, »Jahwe ist der Gott der ganzen Erde. Der Beitrag der außerkanonischen althebräischen Texte zur Rekonstruktion der vorexilischen Religions- und Theologiegeschichte Palästinas, « in Israel zwischen den Mächten. Festschrift für Stefan Timm zum 65. Geburtstag, Hg. Michael Pietsch und Friedhelm Hartenstein, AOAT 364 (Münster: Ugarit-Verlag, 2009): 289-377, 331-333; 354; TUAT.NF 6, 317 (Berlejung). Nunmehr liegt die offizielle Erstpublikation vor: Ze'ev Meshel, Kuntillet 'Ağrud (Ḩorvat Teman). An Iron Age II Religious Site on the Judah-Sinai Border (Jerusalem: Israel Exploration Society, 2012): 98 f. Nr. 3.9. Dazu Blum, »Wandinschriften«: 46 f.; Jaroš, Zeugen, $108 \mathrm{f}$.

224 Die alternative - philologisch allerdings problematischere - Lesung durch Erhard Blum (Blum, »Wandinschriften«: 46 f.; vgl. bereits $\operatorname{CoS}$ 2, 172 mit Anm. 4 [McCarter]) ואיْ פתה : ונתן [...] und hat er nicht seinen Bissen (i. S. v. Brot), so gibt er sein Nötiges (דָּיהו כלבבה ) nach seinem Wunsch« ändert nichts an der hier interessierenden Grundstruktur. Jaroš, Zeugen, 109 deutet פתה als Nomen »einfältig«.

225 Zum Ugaritischen vgl. Kap. 2.1.1.2 Abschn. f, zum Amarna-Kanaanäischen Kap. 2.1.2.3 und zum Phönizischen Kap. 2.2.2.2 Abschn. a.

226 Die Folge Perf. - w-Perf. erscheint im Ugaritischen (Kap. 2.1.1.2 Abschn. f [KTU 2.30, 16-20]) und Phönizischen (Kap. 2.2.2.2 Abschn. a). Vgl. auch die etwas anders geartete Stelle EA 82, 15-20 im Amarna-Kanaanäischen; dazu oben Kap. 2.1.2.3.2 Abschn. 2.d. 
- $\operatorname{Nim}(8): 1 \mathrm{Z} \cdot 3^{227}$

: [die ... (?) zu] kommen,

[... und sie werden / man wird auslöschen ...

Die Stellen sind zu unsicher, um sie für die syntaktische Theoriebildung heranziehen zu können. Man wird aber nicht vorschnell unter Rückgriff auf ein hebräisches Normsystem bestimmte Deutungen a priori ausschließen können - wie die folgenden Beispiele zeigen sollen.

\subsection{2 wa-Perfekt im Neueinsatz auf der Hauptebene des Textes}

Anders im Blick auf den Erhaltungszustand sieht es mit zwei Stellen der längst bekannten Ostraka des frühen 6. Jahrhunderts aus, zu denen mittlerweile ein weiterer Beleg hinzugekommen ist, der - zusammen mit einer größeren Zahl vergleichbarer Ostraka aus dem Antikenhandel stammend - wohl aus der Gegend von H. al-Kōm kommen dürfte und etwa derselben Zeit angehört.

In allen Fällen geht es im weitesten Sinne darum, dass wa-Perfekt auf der Haupttextebene ein neues Thema beginnt und damit am Anfang einer Phrase steht. In jedem Fall geht wenigstens ein weiterer Passus voraus, so dass der Anschluss durch die Konjunktion wa- gerechtfertigt erscheint.

Entscheidend wird hier die temporale Einordnung des jeweiligen Satzes sein.

\subsubsection{Arad-Ostrakon Nr. 3: $\operatorname{Arad}(6): 3^{228}$}

Struktur:

\begin{tabular}{|c|c|c|}
\hline • תן & Imper. & ${ }^{2} \mathrm{Gib}$ (Wein)! \\
\hline 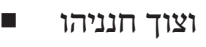 & $w$-Perf. & Und ${ }^{3}$ Ḥananyāhū hat dich beordert ... \\
\hline Iוצרתתד & Perf. cons. & ${ }^{5}$ und belade (Teig) \\
\hline וספר & w-Imper. & ${ }^{6}$ und ${ }^{7}$ zähle (Weizen/Brot) \\
\hline 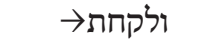 & Perf. cons. & ${ }^{8}$ und nimm ... \\
\hline
\end{tabular}

In eine Reihe von Imperativen unterschiedlicher Thematik eingefügt erscheint im Arad-Ostrakon Nr. 3 in Z. 2-6 der Satz: וצוך חנניהו על בארשבע עْם משא צמדْ חמרם und Ḥananyāhū hat dich nach Beerseba beordert mit der Last eines Eselsgespanns: belade sie mit Teig«.

Mit wa- eingeführtes Perfekt wird durch ebenfalls durch $w a$ - eingeführtes Perfekt im Sinne eines Perf. cons. in Funktion eines Befehls fortgesetzt. Der na-

227 HAE I, 128-130 (Nim[8]:1; Lit.); HI, 392-394 (Nim 1); EP, 329 f.

228 HAE I, 360-363 (Arad[6]:3); HI, 15-18 (Arad 3); EP, 98-102; Weippert, Textbuch, 358 Nr. 205. 
mentlich nicht bekannte Vorgesetzte des in den Arad-Briefen ständig genannten 'Ēlyāšīb rekurriert auf einen Befehl des mit diesem 'Ēlyāšīb etwa gleichrangigen Ḥananyāhū - so

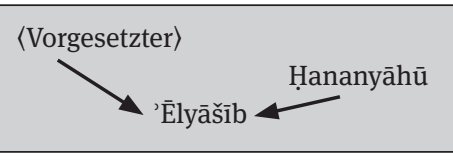
die Relationen nach Ostrakon Nr. 16 - an den diesem zwar etwa gleichrangigen, aber doch weisungsgebundenen 'Ēlyāšīb: Mit vielen anderen wird man hier von einem abgeschlossenen Vorgang reden müssen, der eindeutig in der Vergangenheit liegt: ${ }^{229}$ Sollte ein - letztlich zukünftig verstandenes - Bedingungssatzgefüge vorliegen im Sinne von: »wenn Ḥananyāhū dich beordern wird, so belade zusätzlich mit Teig «, ${ }^{230}$ wäre nicht nur schwer verständlich, weshalb der Vorgesetzte sich auf einen möglichen Befehl eines ihm sogar Untergebenen bezieht und sich damit von diesem von vornherein abhängig macht - obwohl dies nicht ganz auszuschließen ist. Vor allem bleibt die detaillierte Beschreibung des Befehls des Ḥananyāhū unverständlich: Dieser Befehl dürfte also schon ergangen sein; der unbekannte Vorgesetzte schließt sich dem Befehl des Ḥananyāhū mit einem Zusatzauftrag oder der Spezifizierung des Befehls für 'Ēlyāšīb an.

Die Tempusfolge ähnelt derjenigen außerhebräischer Bedingungs- und Temporalsatzgefüge mit Perfekt - auch mit wa- - in beiden Satzteilen, deren absolute Tempuslage nicht automatisch auf die Zukunft festgelegt ist.

Der Befehl Ḥananyāhūs scheint die Voraussetzung für den eigenen Befehl des namentlich nicht bekannten Vorgesetzten zu sein: Die Deutung von וצוך als Umstandssatz zum folgenden Befehl - um eine Deutung als ein einem Lang-Imperfekt gleichwertiges Perf. cons. aufrechterhalten zu können - erscheint schwierig, da der Befehl Ḥananyāhūs in jedem Fall nicht gleichzeitig zum folgenden Befehl des Vorgesetzten ist.

$w a$-Perfekt dient nach dem abgeschlossenen ersten Befehl somit der Einführung einer neuen Thematik - fast dem gebräuchlichen $w^{e}-x$-qatal entsprechend.

229 Zur Diskussion HAE I, 361. Die überwiegende Mehrzahl der Kommentatoren übersetzt manchmal ohne Kommentar zu Tempusgebrauch und Syntax - ebenso vergangen (neben der Erstedition Yohanan Aharoni, Arad Inscriptions [Jerusalem: The Israel Exploration Society, 1981], 17 f. dann u. a. André Lemaire, Inscriptions Hebrä̈ques, Tome I. Les ostraca, LAPO [Jerusalem: Les éditions du cerf, 1977], 163 f. [mit abweichender Folgekonstruktion]; CoS 3, 83 Nr. $3.43 \mathrm{C}$ [Pardee]; Schüle, Syntax, 137; EP, 100; Jaroš, Zeugen, 159). - Dennis Pardee u. a., Handbook of Ancient Hebrew Letters, SBL Sources for Biblical Study 15 (Chico, Cal.: Scholars Press, 1982), 35, James M. Lindenberger, Ancient Aramaic and Hebrew Letters, SBL Writings from the Ancient World Series 4 (Atlanta, Georgia: Scholars Press, 1994), 108, Gogel, Grammar, 266; 270 und HI, $16 \mathrm{f}$. deuten ebenfalls als wa-Perf. im Sinne eines Perf. declarativum / Briefperfekts »hiermit beordert ...«, was allerdings beim Bezug auf eine dritte Person weniger Sinn macht.

230 Weippert, Textbuch, 358 »Und wenn Ḥănanyāhū dich ... beordert, so packe Teig bei ...«. 
Man möchte fast übersetzen: „Was die Tatsache angeht, dass Ḥananyāhū dich beordert hat ..., so belade sie mit Teig«.

\subsubsection{H. al-Kōm / Antikenhandel: Ostrakon (plțyhw-Brief)}

Eindeutiger ist der bereits angesprochene zweite Text, ein Briefostrakon aus H. al-Kōm (»plțhhw-Ostrakon«) aus dem ausgehenden 7. / beginnenden 6. Jahrhundert v. Chr., ${ }^{231}$ der gattungsmäßig genau den üblichen Arad- oder Lachischostraka entspricht:

1

2

3

4

6
An pltyhw:

Und nun: Siehe ich habe dich gesandt.

Dillst du mir heute nicht Bericht erstatten / antworten?! ${ }^{233}$

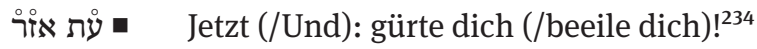

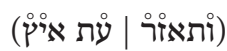

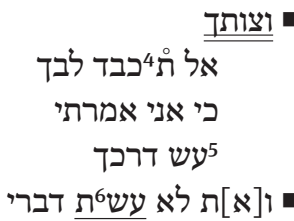

Und ich habe dir befohlen: »Widersetze ${ }^{235}$ dich nicht«, denn ich habe gesagt: Tue deinen Weg!

Aber du, du hast meine Worte nicht getan!

231 André Lemaire und Ada Yardeni, »New Hebrew Ostraca from the Shephelah, « in Biblical Hebrew in its Northwest Semitic Setting, Hg. Steven E. Fassberg und Avi Hurvitz (Winona Lake: Eisenbrauns, 2006): 197-223, 197-200 (Nr. 1); EP, 205-207.

232 Das Perf. שלחתיךist im Kontext wohl tatsächlich vorzeitig und nicht, wie sonst in Briefeinleitungen des Öfteren anzutreffen, als Perfectum declarativum / Koinzidenzfall (»ich sende dich hiermit«) zu verstehen: Der bereits abgesandte Untergebene wird angemahnt, endlich Bericht zu erstatten.

233 Wz. שוב Hi. mit doppeltem Akk. - דָדָ und Zielperson - auch atl. in der Bedeutung »jem. Bericht erstatten; antworten « (Ges. ${ }^{18}$ 239b; 1330b).

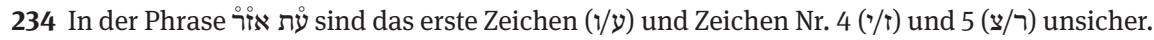
Die Photos bei EP, 206 und Lemaire und Yardeni, »New Ostraca«, Abb. 1 lassen kaum klare Aussagen zu, weshalb EP, 205 auf Transkription und Übersetzung der Passage verzichtet. Denkbar wären die Varianten ותאזר oder, die als Imperativ oder Jussiv mit wa-copulativum etwa denselben Sinn ergäben: eine Aufforderung, sich zu gürten, evt. im Sinne, sich zu beeilen. Im Falle einer Deutung der letzten drei Konsonanten als (mit dann sehr kleinem, wohl teilweise ins Ș geschriebenem Y) käme eine Ableitung von der Wurzel איץ / אוץ in Frage, die im Qal transitiv »jem. drängen, bedrücken«; intransitiv »es eilig haben, sich drängen « (Ges. ${ }^{18} 25 \mathrm{~b}$ ) bedeutet, in Frage (die von Lemaire und Yardeni, »New Ostraca«: 199 mit Anm. 5 empfohlene Deutung als Pi. in gleicher Bedeutung wie Hi. [»in jem. dringen«] dürfte kaum Sinn machen, da ja eine intransitive Bedeutung zu erwarten ist, die nur das Qal aufweist).

235 Faktitives כבד Pi. oder kausatives Hi. zusammen mit לב in der Bedeutung »das Herz verstocken, verhärten « (Ges. ${ }^{18}$ 523b) mit dem Ergebnis: »hartnäckig/widerspenstig sein « (Lemaire 
Der Befehlshaber hat seinen Untergebenen ausgesandt (Z. 1 f. שלחתיך) - mit Perfekt formuliert -, erwartet daraufhin einen Bericht, der offenbar ausbleibt (Z. 2f.), und drängt nun den Untergebenen (Z. 3).

Mit וצותך (Z. 3) wird nun offensichtlich auf den früher ergangenen Befehl, sich nicht zu widersetzen, rekurriert: »Und ich habe dir befohlen «. ${ }^{236}$ Nach dem Zitat dieses früheren Befehls (Z. 3-5) folgt mit einfachem Perfekt in Zweitstellung der darauf rekurrierende Vorwurf, nicht gehorcht zu haben (Z. $5 \mathrm{f}$.): »aber du, du hast meine Worte nicht getan!«. Der Vorwurf macht endgültig deutlich, dass der Befehl, auf den er sich bezieht, in der Vergangenheit lag.

wa- mit Perfekt leitet ein neues Unterthema ein. Eine Deutung als Begleitumstand zum vorhergehenden Aussendungsbefehl - »ich habe dich geschickt und dir dabei befohlen « - scheitert wohl an den dazwischenliegenden Befehlen, vielleicht sogar עת (masoretisch עתה (masoring der Hauptebene des Textes. Wollte man versuchen, um ein Perf. cons. im Sinne eines Lang-Imperfekts aufrechtzuerhalten, das Ganze iterativisch zu verstehen: »ich habe dir immer wieder befohlen «, würde man sich dies doch durch eine entsprechende Temporalbestimmung deutlicher zum Ausdruck gebracht vorstellen.

Eine Deutung als Konjunktion wa- mit anschließend konstatierendem Perfekt könnte also zumindest nicht auszuschließen sein.

\subsubsection{Arad-Ostrakon Nr. 16: Arad(6):16}

Ein dritter Text, Arad-Ostrakon Nr. 16 ${ }^{237}$, weist in Z. 4 wa-Perfekt nach einer Temporalbestimmung - realisiert als Inf. cstr. mit Präp. כ quasi als Temporalsatzersatz - auf.

und Yardeni, »New Ostraca«: 199: »to be unresponsive, to persist/harden his own ideas«). - Im Falle einer Lesung יכבד müsste man eine Qal- oder Nif.-Bedeutung annehmen: »dein Herz möge

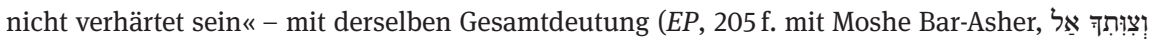

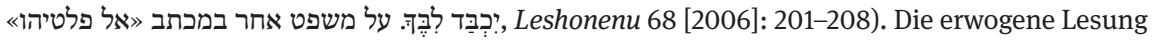

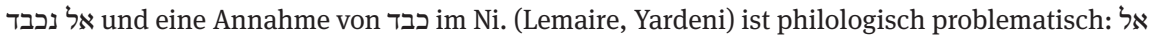

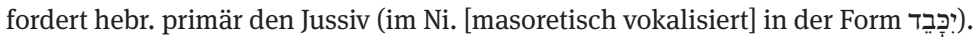

236 Lemaire und Yardeni, »New Ostraca«: $198 \mathrm{f}$. (»I ordered you«). Ohne weiteren Kommentar zum Tempus gegenwärtig ([?] Perf. declarativum) übersetzt EP, 205 (»And [...] I order / urge you ...«).

237 Aharoni, Arad Inscriptions, 30 f. (Nr. 16); Pardee, Handbook, 48-50; Lemaire, Inscriptions, 172-174; HAE I, 379 f. (Arad[8]:16; Lit.); HI, 31-34 (Arad 16); EP, 113-116; Weippert, Textbuch, 358 f. (Nr. 206). 
- $\operatorname{Arad}(6): 16$

$$
\begin{aligned}
& \text { : Und nun: } \\
& \text { Gleich als ich wegging aus deinem Haus, } \\
& \text { da sandte ich das Silber, } 8 \text { Schekel, an die }
\end{aligned}
$$

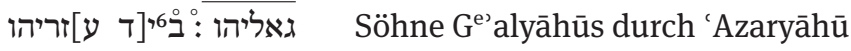

Absender ist der bereits erwähnte etwa gleichrangige Kollege 'Ēlyāšībs mit Namen Ḥananyāhū, Empfänger wieder eben dieser 'Ēlyāšīb. Das Briefcorpus ab Z. 3 beginnt sofort mit dem Satz - eingeleitet mit der üblichen Corpuseinleitung ( ועצ'usw. »gleich als ich wegging

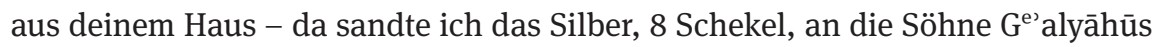
durch 'Azaryāhū ...«. Beides, Temporalbestimmung wie auch wa-Perfekt, sind nur als vom Schreiber aus gesehen vorzeitige Ereignisse $\mathrm{zu}$ verstehen. ${ }^{238}$ Ein gleichzeitiger Umstandssatz im Sinne eines Perf. cons. als Alloform zum LangImperfekt oder überhaupt als Bei- oder Unterordnung unter das Haupttempus kommt nicht in Frage - es gibt nichts, wozu ושלחת gleichzeitig sein könnte.

Faktisch ist ושלחתי Nachsatz zu einem Temporalsatz, aber in der Vergangenheit.

Auch der Versuch, wa-Perfekt als Perf. cons. in die Zukunft zu verlagern, scheitert hier: Man müsste übersetzen - und dies wurde auch vorgeschlagen -: »wenn ich hinausgehen werde aus deinem Haus, dann werde / will ich das Silber schicken ... « usw. ${ }^{239}$ Es macht aber keinen Sinn, eine angekündigte Aktion temporal von einer anderen eigenen Aktion abhängig zu machen - die Prp. כִ vor Inf. cstr. kann ja nicht konditional verstanden werden. ${ }^{240}$ Würde sich der Absender gerade bei seinem Kollegen im Haus befinden, könnte eine solche bedingte Ankündigung noch verständlich sein: "gleich wenn ich morgen wieder weggehen werde, werde ich das Silber schicken«.

238 Die Verbform ושלחתי wird im Grunde von allen Bearbeitern - oft kommentarlos - vorzeitig übersetzt, etwa Aharoni, Arad Inscriptions, 30; Lemaire, Inscriptions, 172 (»comme je suis sorti ... alors j’ai envoyé ...«); Pardee, »Letters«: 310 f.; ders., Handbook, 48 (»when I left ... I sent ...«); HI, 32; 33 (»when I departed ..., I sent ...«); EP, 114. - Weippert, Textbuch, 359 lässt die Übersetzung offen.

239 So vor allem $\operatorname{CoS} 3,83$ f. Nr. 3.43G mit Anm. 21 (Pardee) (»when I leave your house I will send the money«), danach Gogel, Grammar, 263; 267.

240 Die Prp. כ̦ vor Inf. cstr. dient nur selten zur Bezeichnung eines Vergleichs, vor allem bezeichnet sie temporal die unmittelbar zurückliegende Vergangenheit »sobald als«, auch Gleichzeitiges »als; wenn/während « (Ges. ${ }^{18}$ 520b; GK § 114e; Rudolph Meyer, Hebräische Grammatik [Berlin, New York: de Gruyter, 1992 (Nachdruck von ${ }^{31972)], ~ § ~ 102,3 ~ u . ~ a .) . ~ K o n d i t i o n a l e ~ B e d e u t u n g ~ k a n n ~}$ כ̦ vor Inf. cstr. nicht annehmen. 
Der Absender und Schreiber des Briefes schreibt aber zwangsläufig von einem anderen Ort als der Empfänger und damit aus größerer Distanz, sonst wäre kein Brief nötig. Er würde demnach ankündigen: »wenn ich demnächst zu Dir kommen werde (was gar nicht gesagt ist) und dann wieder von Dir und deinem Haus fortgehen werde, dann werde ich das Silber schicken«. Wozu dann die ganze Konditionierung? Der Absender könnte einfach ankündigen, das Silber zu schicken.

Rückblickend macht das Ganze aber Sinn: »als ich kürzlich bei dir war, habe ich - eventuell: wie verabredet - gleich nach meinem Weggang das Silber geschickt «.

Es scheint also wohl doch einfaches, perfektiv / vorzeitig $\mathrm{zu}$ verstehendes Perfekt vorzuliegen - kein Äquivalent zum Lang-Imperfekt.

\subsubsection{H. al-Kōm / Antikenhandel (Ostrakon)}

Möglicherweise gehört auch noch die ohne Kontext erhaltene Verbform ושלחתך »und ich werde dich senden« in Z. 10 der Vorderseite der sehr fragmentarisch erhaltenen, zuerst geschriebenen Inschrift eines Palimpsestes hierher. Das unten näher diskutierte, aus dem Antikenhandel stammende Ostrakon (»Silver, Pistachio and Grain «-Ostrakon) könnte aus H. al-Kōm kommen. ${ }^{241}$

\subsubsection{Zum Vergleich: Horvat 'Uzzā: edomitisches Ostrakon}

Die Abfolge $w a-+$ Perfekt begegnet zudem in der Grußformel (Briefkopf) eines Briefes auf dem edomitischen Ostrakon aus H. Gazze / Horvat 'Uzzā. ${ }^{242}$ Auf die geläufige Frage nach dem Wohlbefinden (השלם את) folgt der Segensgruß והברכתך לקוס ״und ich segne dich hiermit vor Qaus«. ${ }^{243}$ Die Formel entspricht im hebräischen Corpus einfachem Perfekt ohne die Konj. wa-: ברכתך ליהוה וich segne dich hiermit vor Jahwe« u. ä. ${ }^{244}$ Im Kontext des Segensgrußes kommt nur ein Verständnis als Perf. declarativum / Koinzidenzfall in Frage; weder futurische noch durativisch-iterativische Deutungen machen Sinn und sind von den Parallelformeln anderer Briefe mit einfachem Perfekt auch ausgeschlossen: Perfekt und wa-Per-

241 EP, 202-205. Dazu unten Kap. 4.2.2 Abschn. c.

242 Vgl. Itzhaq Beit-Arieh und Bruce Cresson, »An Edomite Ostracon from Horvat 'Uza, «TA 12 (1985): 96-101; Itzhaq Beit-Arieh, Horvat 'Uza and Horvat Radum. Two Fortresses in the Biblical Negev, Tel Aviv University. Sonia and Marco Nadler Institute of Archaeology. Monograph Series 25 (Tel Aviv: Tel Aviv University, 2007): 133-137; Felice Israel, »Supplementum Idumeum I, « RivBibIt 35 (1987): 337-356, 339-342; TUAT.NF 3, 359 (Kottsieper); EP, 351-354.

243 Das Edomitische benutzt das Verbum ברד im Kausativstamm statt des bibl.-hebr. üblichen $\mathrm{Pi}$.

244 Zur Formel - auch im Phönizischen - vgl. Renz, HAE II/1, 30-32; 10 Anm. und ders., "Jahwe«: 330 f. (Lit.). 
fekt sind hier gleichbedeutend. Umgekehrt ist in diesem Kontext והברכתך keine אברכך Alloform zu.

\subsubsection{Ausblick: wa-Perfekt am Abschluss einer Erzählkette}

Nach alledem - aber dies soll hier nicht das Hauptthema sein - könnte man auch die oftmals diskutierte Verwendung von wa-Perfekt in der Petition von Meșad Hašabyāhū nochmals überdenken.

- $\operatorname{MHas}(7): 1 \mathrm{Z} .2-6^{245}$

a

$\mathrm{b}$

C

d
Dein Diener ist Schnitter.

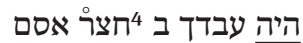

ויקצר עבדך עבד עיר

ואיכל כיכל

ואססֵْ כימْם לפני שבאת
Als dein Diener in $\langle\mathrm{ON}\rangle$ war, da erntete dein Diener und maß ab und häufte (währenddessen/ schließlich) in den Speicher wie (alle) Tage vor dem Arbeitsende (Sabbat)

- In verkürzter Form wiederholt sich die Konstruktion nochmals in Z. 6-7: 246

$c^{\prime}$

d
6כאשר כל [ע]בדך את קצרלה

ואיסם כימם

$$
\text { ויבא הושעיהו בן שבי }
$$

Gerade als dein Diener seine Ernte abmaß und aufhäufte wie (alle) Tage, da kam Hauša 'yāhū ...

Hier geht es um die auffällige Verwendung von wa-Perfekt am Abschluss einer Erzählkette: Auf a) einen Nominalsatz zur Darstellung eines generellen Sachverhalts - der Berufsbezeichnung - folgt b) mit einleitendem Perfekt היה ein solchermaßen verzeiteter Nominalsatz zur Ortsangabe, ${ }^{247}$ dem dann c) eine Nar-

\footnotetext{
245 Neben der oben in Kap. 3.2.2 Abschn. 2 genannten Lit. (HAE I, 315-329; HI, 358-370; CoS 3, 77 f.; EP, 156-163; Weippert, Textbuch, 370-372) vgl. - auch zur Übersetzung und Deutung der Verbalform ואסם - bes. Spieckermann, Juda, 129f. mit Anm. 215 u. 216; Weippert, »Petition«: 449-466, dann allgemein KAI Nr. 200 (Röllig); John C. L. Gibson, Textbook of Syrian Semitic Inscription. Bd. I. Hebrew and Moabite Inscriptions (Oxford: Clarendon Press, 1971): 26-30; Lemaire, Inscriptions, 259-268; Pardee, Handbook, 15-24; CoS 3, 77 f. (Pardee); Klaas A. D. Smelik, Historische Dokumente aus dem alten Israel (Göttingen: Vandenhoeck \& Ruprecht, 1987), 87-93, Übersetzung 90; Jaroš, Zeugen, 146-149.
}

246 Zur Passage s. o. Kap. 3.2.2 Abschn. 2.

247 Zur Konstruktion s. o. Kap. 3.3. 
rativkette $^{248}$ folgt - die für die Argumentation offenbar wichtige vollständige Abfolge der Erntearbeiten vor dem Feierabend. Die verkürzte Wiederholung im Temporalsatz V. 6 f. kennt entsprechend Perfekta (ć). Auffällig ist d) das abschließende ואסם - offenkundig wa- mit Perfekt - falls man nicht, wie vom Autor selbst zunächst bevorzugt, einen Inf. abs. als Ersatz für eine finite Verbalform hier sehen möchte: ${ }^{249}$ Dies ist nach Ausweis alttestamentlicher Parallelen möglich und auch keineswegs auszuschließen, wird aber nie den Beigeschmack einer Notlösung verlieren. ${ }^{250}$

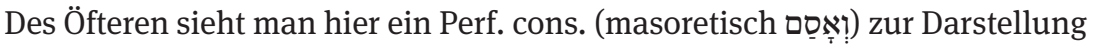
von Gleichzeitigem, wie es das Lang-Imperfekt könnte; konkret spricht man von einem Umstandssatz, von Begleitumständen, Hintergrundinformationen u. ä.:251 Die Übersetzung wäre damit: »er erntete und maß ab, während/wobei er einlagerte wie (alle) Tage«.

Etwas unbefriedigend bleibt natürlich auch diese Lösung: וְאָסֵ ist hier kein Äquivalent zum Lang-Imperfekt, ${ }^{252}$ es geht nicht um einen Zustandssatz auf der Hintergrundebene. Vielmehr gehört וָאָסָם gerade zur Hauptaussage, zur Hauptebene: Alles läuft ja auf den letzten Vorgang, das Einlagern hinaus - der Verfasser beteuert, seine Arbeit vollständig abgeschlossen zu haben und zu Unrecht gepfändet worden zu sein.

$248 \mathrm{Zu}$ den eingebetteten Narrativen s. o. Kap. 3.2.2 Abschn. 2.

249 Mit Frank M. Cross, »Epigraphic Notes on Hebrew Documents of the Eighth-Sixth Centuries B. C.: II. The Murabba ât Papyrus and the Letter Found near Yabneh-Yam, « BASOR 165 (1962): 34-46, 44 Anm. 43; KAI II, 200 (Röllig) zu Nr. 200 (»als Ausdruck einer resultativen Handlung «); Gibson, Textbook, 29 erwogen von Renz, HAE I, 325 mit Anm. 2; HI, 361 (alternativ: Perf. mit wacopulativum); EP, 161 (alternativ: Perf. mit wa-copulativum) sowie Gogel, Grammar, 271; 267 mit Anm. 30.

250 Das Argument, die vorliegende Stelle wäre dann der einzige epigraphisch-hebr. Beleg für den Inf. abs. in Funktion einer finiten Verbalform, ist allerdings kaum stichhaltig, da der Inf. abs. als Ersatz für den Imper. durchaus mehrfach nachzuweisen ist (Gogel, Grammar, 271) und derselbe Inf.-Typ durchaus auch im narrativen Gebrauch im Kanaanäischen vor und gleichzeitig mit dem Hebräischen erscheint, im Ugaritischen (UG 491 f. § 73.531), Amarna-Kanaanäischen (CAT 2, 383-388; KAA 88 4.6.3) und - häufig - im Phönizischen ( $P P G \S 267 \mathrm{~b})$.

251 Ausführlich begründet von Weippert, »Petition«: 458-466, speziell 465 (»Begleit- oder Hintergrundhandlung«; Übersetzung: »während er den Speicher füllte« [ebd. 460; vgl. Weippert, Textbuch, 371]), pointiert auch Blum, »Verbalsystem«: passim und 124-126. - Ebenso als Perf. cons., aber mit durativischer Bedeutung, deutet die Form André Lemaire, »L’Ostracon de Meșad Ḥashavyahu (Yavneh-Yam) replacé dans son context, « Sem. 21 (1971): 57-79, 64, dann auch Lemaire, Inscriptions, 259-268. - Modal deuten das Perf. cons. Lienhard Delekat, »Ein Bittschriftentwurf eines Sabbatschänders (KAI 200), « Bibl. 51 (1970): 453-470, 461 f.; Krüger, »KAI 200«: $36 \mathrm{f}$. »und wollte einlagern«.

252 Dies unterstellt Blum, »Verbalsystem «: 124-126 und passim, nach dessen System wa- + vorzeitiges Perf. (wie auch wa- + Lang-Ipf.) a priori ausgeschlossen wäre. 
Es geht allerdings auch nicht - wie eher selten vorgeschlagen - um ein narratives wa-Perfekt, ${ }^{253}$ also einen Ersatz für den Narrativ wa-yaqtul. Dieser wäre wohl im Kontext denkbar, ויאסם ist aber - doch wohl ausdrücklich - nicht gewählt worden. $w a$-Perfekt hat auch in den vorgenannten Beispielen nie die gleiche Funktion wie der Narrativ, das vor allem den Progress zum Ausdruck bringende Erzähltempus. ${ }^{254}$

Daher wird auch bei einer Deutung als wa-Perfekt zu Recht auf dessen nicht konsekutive Funktion hingewiesen ${ }^{255}-w a$ - bliebe einfaches $w a$-copulativum..$^{256}$ Wenn man solchermaßen am Schluss der Erzählkette wieder aus der Erzählerperspektive ansetzt und mit vorzeitigem Tempus (Perfekt) in die Vergangenheit zurückgeht, würde eine Handlung bezeichnet, die gleichberechtigt und gleichzeitig zum Vorhergehenden ist ${ }^{257}$ - ohne dass man sie auf eine Hintergrundebene schieben würde. Es ginge um parallele Vorgänge. Dass das Einlagern auch nach dieser Deutung kein weiterer Schritt mehr ist, bleibt aber logisch schwierig: Es läuft eigentlich alles auf das Einlagern als Abschluss hinaus.

Am besten passt - in Weiterführung des Vorgenannten - vorläufig die Funktion des Perfekts als Abschluss einer Narrativkette, wie sie im Ugaritischen belegt ist. ${ }^{258}$ Dort werden hier und da »Narrativ«-Ketten - wa- mit Kurz-Imperfekt - durch einfache Perfekta eingeleitet und auch abgeschlossen, wobei das Abschließende

253 Die Form ואסם wird entsprechend - unter Rückgriff auf Meyer, »Erzählungsstil«: 114-123, 122; sowie ders., Grammatik III $\S 100$, 3e (§101,7) - von Spieckermann, Juda, (125-)129f. mit Anm. 215 u. 216 als Äquivalent zum Narrativ verstanden (ebd. 125: »Ersatz für das Impf. cons. «) und mit bereits vorexilisch wirksamem aram. Einfluss erklärt. - Einfach vergangen unter Annahme von einfachem Perf. mit wa-copulativum übersetzt HI, 359; 361 (alternativ: Inf. abs.), einfach narrativisch etwa Smelik, Dokumente, 90; Jaroš, Zeugen, $147 \mathrm{f}$.

254 Die Abgrenzung vom späteren, mittelhebräischen Sprachgebrauch war dann auch immer der Grund für die Ablehnung der Existenz eines Perf. mit wa-copulativum und für daraus resultierende Deutungsversuche als Perf. cons.

255 So ausdrücklich Dennis Pardee (Handbook, 21: »non-consecutive«) und Shmuel Ahituv (EP, 161).

$256 » . .$. joined by the simple conjunction to the preceding verb ...« $(E P, 161)$.

257 Shmuel Ahituv: »By this means the forms represent an action that is coeval with the measuring. One measured in order to store. The storing was not looked upon as a further step in the process but as part of the same process ... « (EP, 161. Der Hinweis auf Gen 2,6 ist aber problematisch: Dort wird völlig regelkonform Lang-Ipf. durch Perf. cons. fortgeführt). - Ähnlich deutet Dennis Pardee die letzte Aktion als »subservient to the principal actions« (Pardee, Handbook, 21), die Übersetzung als Abfolge von Ereignissen (auch $\operatorname{CoS} 3$, $77 \mathrm{f}$. [Pardee]) zeigt, dass keine Hintergrundinformation gemeint ist. - Schüle, Syntax, 133 f. u.ö. deutet die Entstehung des Perf. cons. und schwierigere Stellen wie die vorliegende von einer extemporal stativischen Bedeutung der Afformativkonjugation auch bei fientischen Verben her. Im Endeffekt würden so ebenfalls gleichzeitige Begleitumstände - speziell in einem explikativen Sinne verstanden - bezeichnet. 258 Bezeichnenderweise hat GK §112b Anm. 1 (S. 343 f.) versucht, die Entstehung des Perf. cons. aus einer Bezeichnung für den »Abschluß (die endgültige Folge) einer in der Vergangen- 
gleichzeitig auch die Zusammenfassung darstellt. ${ }^{259}$ Man setzt demnach - ähnlich wie bei den vorher genannten Beispieltexten - wieder aus der Gegenwart des Erzählers ein und bringt dann perfektiv / konstatierend das Ganze zum Abschluss. Gerade in dieser Funktion ist allerdings auch die bereits genannte Deutung als Inf. abs. nicht aus der Diskussion.

\subsubsection{Summe}

In all diesen Fällen hätte das von Stefan Bombeck und neuerdings Holger Gzella postulierte Element des Innehaltens, des Stillstandes der Konstruktion wa-Perfekt seine Berechtigung ${ }^{260}$ - bei aller Kritik, die sonst an der konsequenten Verfolgung dieses Prinzips geäußert wurde. ${ }^{261}$ Funktional ersetzt wa-Perfekt jedenfalls nicht den Narrativ im Sinne eines Progresstempus, sondern wäre eher mit biblisch-hebräischem wa-x-qatal (וְהוּא קָטֵל) zu vergleichen. ${ }^{262}$ Die Bedeutungen lassen sich ebensowenig auf einen (extemporalen) Stativ zurückführen. ${ }^{263}$

heit andauernden (oder wiederholten) Handlung (Hervorhebung vom Vf. selbst) heraus zu erklären.

259 Dazu oben Kap. 2.1.1.2 Abschn. c - N. B. besonders die Beispiele bei UG $\S 76.524 .3$ Abschn. b und c, etwa die Bewirtungsszene der Aqht-Legende KTU 1.17 II 26-42 (André Caquot u. a., Textes Ougaritiques. Tome I. Mythes et Légendes, LAPO [Paris: Cerf, 1974], 425 f.; Gregorio del Olmo Lete, Mitos y Leyendas de Canaan [Madrid: Ediciones Christiandad, 1981], 372 f.; Johannes C. de Moor, An Anthology of Religious Texts from Ugarit, NISABA 17 [Leiden: Brill, 1987], 231 f.; TUAT III 1266 f. [Dietrich/Loretz]; Nick Wyatt, Religious Texts from Ugarit, The Biblical Seminar 53 [London/New York: Sheffield Press, $\left.{ }^{2} 2002\right], 264$ f.): 1. Einleitung (Z. 26 f.): Perfekt: ' $r b$ bbth ktrt »Es traten in sein Haus die Kôtarātu-Göttinen«. - 2. Mittelteil (Z. 27b-38): Einzelhandlungen, Kurz-Imperfekta (auch mit Konj. wa-): ảpnk dnỉ ... ảlp yțbh »dann schlachtete (țbh) Dani'ilu einen Stier« - yšl ḥm »er gab zu essen « (lhm Š-Stamm) - wyššq »und gab zu trinken« (šqy Š-Stamm) - dies wiederholt sich für den 1./2., 3./4. und 5./6. Tag. - 3. Höhepunkt und Schluss (Z. 39-42): Perfekt: mk bšb ymm $t b^{`}$ bbth ktrtt »siehe, am 7. Tag gingen ( $t b$ ) die Kôtarātu-Göttinnen aus seinem Haus«: Die Durchnummerierung der Ereignisse macht deutlich, dass gerade auch das letzte Erzähl-Element, der 7. Tag, nicht zum Hintergrund, sondern zur eigentlichen Erzählung gehört. Alles läuft auf diesen letzten Tag hinaus. Das Perf. der Einleitung könnte man dagegen vorzeitig verstehen: »die Kôtarātu-Göttinen waren in sein Haus getreten« (Caquot u. a., Textes, 425; Wyatt, Texts, 264). Der ganzen Passage gehen Kurz-Ipf. voraus.

260 Holger Bombeck, «Das althebräische w-Perf. für Gegenwart und Vergangenheit in den hinteren Propheten und den Psalmen, « in Sachverhalt und Zeitbezug. Semitistische und alttestamentliche Studien. Adolf Denz zum 65. Geburtstag, Hg. Rüdiger Bartelmus und Norbert Nebes, Jenaer Beiträge zum Vorderen Orient 4 (Wiesbaden: Harrassowitz, 2001): 21-34, 21; 26 ff.; 32-34; Gzella, Tempus, 319.

261 Blum, »Verbalsystem«: 127 mit Anm. 96.

262 Die Funktion dieser Konstruktion beschreibt Gross, wayyiqțol, 164 entsprechend als »Regress « in ausdrücklichem Gegensatz zum Narrativ.

263 Unter Absehung der immer in der Diskussion bleibenden Stelle MHas(7):1 Z. 2-6. 
Möglicherweise wird man doch den vielleicht unterschiedlichen Sprachgebrauch in verschiedenen Redeformen bzw. Textcorpora zur Erklärung mit heranziehen können. Wenn die hier zugrunde liegende Verwaltungsprosa ohnehin kaum Narrative kennt und das Perfekt dominiert, könnte ein wa-Perfekt in einer dem Perfekt vergleichbaren Verwendung vielleicht nicht allzu auffällig sein. ${ }^{264}$

Die genannten Verwendungsweisen von wa-Perfekt einschließlich der Verwendung im Nachsatz von Bedingungssätzen können aber leicht erklären, wie daraus das spätere Perf. cons. entstanden ist.

\subsection{Dem Biblisch-Hebräischen nahekommende oder entsprechende Verwendungen von wa-Perfekt}

Damit kann man sich nun auch kurz den Verwendungen von wa-Perfekt zuwenden, die weitgehend denjenigen des Biblisch-Hebräischen entsprechen. ${ }^{265}$

\subsection{1 wa-Perfekt zur Fortsetzung auslösender Modi}

Perf. cons. - so der Einfachheit halber ab jetzt genannt - dient im InschriftlichHebräischen der Fortführung auslösender Modi, so zunächst der Weiterführung von Imperativen und des Inf. abs. als Ersatz eines Imperativs, vielleicht des Jussivs. $^{266}$

264 In eine ähnliche Richtung scheinen teilweise die neueren Deutungen der einschlägigen alttestamentlichen Stellen zu kopulativem wa-Perf. zu gehen, wenn etwa im Kontext von II Reg 23 (und II Reg 18,4) wa-Perf. als Tempus gewertet wird, durch das das nicht-progredierende Nebeneinanderstellen vergangener Sachverhalte bezeichnet wird (etwa Christof Hardmeier, »König Joschija in der Klimax des DtrG [II Reg 22f.] und das vordtr Dokument einer Kultreform am Residenzort [23,4-15*], « in Erzählte Geschichte. Beiträge zur narrativen Kultur im alten Israel, Hg. Rüdiger Lux, BThSt 40 [Neukirchen-Vluyn: Neukirchener, 2000], 81-145, 124 f. [»im auf- nicht erzählenden ו-AK-Stil gehalten«]; Pietsch, »Tempus«: 176f. [1.»Einführung einer Begleit- und Nebenhandlung«, 2. »listenartige Aufzählung von Einzelmaßnahmen«], zur Sache auch $161 \mathrm{f}$. Forschungsüberblick: 163-169; Hoffmann, Einführung, 568f. [»listenartige Aufzählungen von Handlungen, die nicht in zeitlicher Abfolge stehen «]) oder wa-Perf. als resultatives Abschlusstempus gewertet wird (Klaus Koch, »Gefüge und Herkunft des Berichts über die Kultreformen des Königs Josia. Zugleich ein Beitrag zur Bestimmung hebräischer sTempora`, « in Alttestamentlicher Glaube und biblische Theologie. Festschrift für Horst Dietrich Preuss zum 65. Geburtstag, Hg. Jutta Hausmann und Hans-Jürgen Zobel [Stuttgart: Kohlhammer, 1992]: 80-92, 83 f.; 86 f.; 89 ff.).

265 Vgl. auch die Übersicht bei Gogel, Grammar, 260-267.

266 Dazu auch Gogel, Grammar, 265-267 und bes. Johannes Friedrich Diehl, Die Fortführung des Imperativs im Biblischen Hebräisch, AOAT 286 (Münster: Ugarit-Verlag, 2004): 223-303, speziell 292-294. 


\subsubsection{Perfectum consecutivum zur Fortführung auslösender Modi bei gleichem Subjekt}

Bei gleichem Subjekt stellt Perf. cons. dabei einfach die Fortsetzung des Befehls dar - ohne dass hier auf Einzelheiten einzugehen wäre. Dies stellt gegenüber dem älteren Kanaanäischen und überhaupt den voreisenzeitlichen Sprachen SyrienPalästinas eine Innovation dar. ${ }^{267}$

nach Imperativ ${ }^{268}$

$\operatorname{Arad}(6): 2,5 \mathrm{f}$.

$\operatorname{Arad}(6): 3,6-8$

$\operatorname{Arad}(6): 17,1-4$

$\operatorname{Arad}(6): 24,13$

$\operatorname{Mur}(7): 1,4^{269}$

nach Inf. abs.

$\operatorname{Arad}(6): 7,6$

H. al-Kōm (? $)^{270}$

nach wa- und Jussiv

$\operatorname{MHas}(7): 1,14^{272}$

$$
\begin{aligned}
\text { מלא / והסבת / } & \text { fülle - und lass bringen } \\
\text { ולקפר / ולקחת } & \text { geh zähle - und nimm } \\
\text { ולקחת } & \text { ?? - und nehmt } \\
\text { ורעלעת } & \text { und weide (?) }
\end{aligned}
$$

gib - und schreibe נתן / וחקרת / וכתחת / וֹעْדْת

gib - und erforsche - und verab-

rede / triff dich mit ... ${ }^{271}$

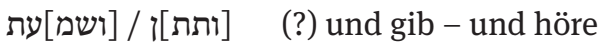

267 Das Amarna-Kanaanäische kannte die Folge $u$-Perf. nur in finalem Sinne zur Bezeichnung einer aus dem Befehl resultierenden Folgehandlung (Kap. 2.1.2.3.4 und das folgende Kap. 4.2.1.2). $268 \mathrm{Zu}$ den im Folgenden nur tabellarisch zitierten Inschriften vgl. die ausführlichen Diskussionen in $H A E$ und $H I$ unter der entsprechenden Signatur.

269 Zum unsicheren und abgebrochenen Kontext vgl. HAE I, 285 (Mur[7]:1); HI, 381 f. (Mur 1).

270 Ostrakon aus dem Antikenhandel (»Nôqědîm-Ostrakon«), möglicherweise aus H. al-Kōm, datiert ins ausgehende 7. oder frühe 6. Jh. (den späten Arad- und Lachisch-Ostraka entsprechend). In den Z. 8-10 Rs. 1-2 begegnet eine typische Befehlsserie, beginnend mit Inf. abs. נתן, gefolgt von zwei Perf. cons. Zum Text siehe Esther und Hanan Eshel, "A Late Iron Age Hebrew Letter Containing the Word Nôqĕdîm, « in Birkat Shalom. Studies in the Bible, Ancient Near Eastern Literature, and Postbiblical Judaism. Presented to Shalom M. Paul on the Occasion of His Seventieth Birthday, Ed. Chaim Cohen u. a., 2 Bde. (Winona Lake, IN: Eisenbrauns, 2008): 571-584; EP, 194-199.

271 Wohl Nif. Perf. cons. v.d. Wz. יעד.

272 Zur völlig unsicheren Stelle vgl. die Diskussion bei HAE I, 329 und HI, 367. Im Anschluss an Joseph Naveh, »Some Notes on the Reading of the Meșad Ḥashavyahu Letter, «IEJ 14 (1964): $158 \mathrm{f}$. ergänzen Weippert, »Petition«: 459; 462 und EP, 159 f.: והש[]]. 


\subsubsection{Perfectum consecutivum zur Fortführung auslösender Modi mit wechselndem Subjekt}

Mit wechselndem Subjekt, so Arad-Ostrakon Nr. 24, kann Perf. cons. wie biblischhebräisch dem Nachsatz einfach finale Bedeutung verleihen. Dies hat seine Vorläufer auch im älteren Kanaanäischen, wie die Amarna-Briefe zeigen. ${ }^{273}$

- $\operatorname{Arad}(6): 24,13-16\left(=\right.$ Rs. $\left.2^{\prime}-5^{\prime}\right)$

(nehmt) - und schickt sie - damit er sie übergibt in die Hand des $\langle\text { SN }\rangle^{274}$

\subsubsection{Perfectum consecutivum zur Realisierung eines Befehls nach Bedingungssätzen und Vergleichbarem}

Etwas verselbstständigt erscheint Perf. cons. auch epigraphisch-hebräisch zur Realisierung von Befehlen ohne vorausgehenden Imper. nach Bedingungssätzen oder die Voraussetzung für den Befehl beinhaltenden Aussagen, deren unmittelbare Folge der Befehl darstellt. ${ }^{275}$

a) Arad-Ostrakon Nr. 2 kennt in Z. 7 einen Befehl, der von einem nominalen Bedingungssatz abhängig ist - freilich eingebettet in eine Serie von Befehlen.

$\operatorname{Arad}(6): 2,7 \mathrm{f} .276$

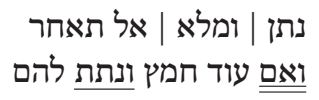

Gib - fülle - zögere nicht und wenn noch Weinessig/Sauerteig da ist, dann gib ihnen (davon)

273 Dazu oben Kap. 2.1.2.3.4.

274 Einfach jussivisch / futurisch übersetzen etwa HI, 49; EP, 128; Weippert, Textbuch, $355 \mathrm{f}$. (Nr. 199).

275 Gogel, Grammar, 263 erwog in Anlehnung an Dennis Pardee, auch in Lachisch-Ostrakon Nr. 4 Z. 9-10 (Lak[6]:4) ein volitiv zu übersetzendes Perf. cons. nach einem Bedingungssatz zu sehen: ... כי אם בתסבת הבקר [י[בْ[א] וידע כי עdenn wenn er im Verlauf des morgigen Vormittags kommen wird, wird/soll er wissen, dass ...«. Wahrscheinlich ist aber anders abzutrennen und in der Bedeutung "vielmehr« zum Vorhergehenden zu ziehen (vgl. HAE I, 422 mit Anm. 2; ähnlich HI, 315; 318; EP, 70; 76; Weippert, Textbuch, 423 Nr. 263).

276 wa-Perf. ונתת wird überwiegend imperativisch übersetzt, vgl. HAE I, 360 (Lit.); EP, 96; 98 (»continuation of a command»); HI, 13 (»you shall ...»); Weippert, Textbuch, 356 Nr. 201. 
b) Auch das Arad-Ostrakon Nr. 3 führt das bereits diskutierte wa-Perfekt »und Hananyāhū hat dich beordert nach Beerseba ... « ${ }^{277}$ fort durch den Befehl »und belade sie mit Teig«,

- $\operatorname{Arad}(6): 3,5 \mathrm{f}$.

und Hananyāhū hat dich beordert ... und belade sie mit Teig

c) In unsicherem Kontext begegnet in einem bereits genannten Ostrakon (»Nôqĕdîm«-Ostrakon) ${ }^{279}$ aus dem Antikenhandel, das zu der großen Gruppe der letztlich aus H. al-Kōm stammenden Texte gehört, in Z. $7 \mathrm{f}$. die wohl als Auftrag zu verstehende Wendung: ידעת מה תעשה וund du sollst wissen, was du zu tun hast « - in einem Ostrakon, das ohnehin von Aufträgen beherrscht wird. ${ }^{280}$ Der vorausgehende Kontext, Z. 5-7, ist leider sehr unsicher: ... אל][כם פניהם (Z. 5 f.) »Zu euch ist ihr Interesse gerichtet ...« o. ä., falls nicht in der Lakune noch Buchstaben zu ergänzen sind.

Nicht ganz auszuschließen ist ein Verständnis als wa- mit konstatierendem Perfekt. Das resultativ zu verstehende Perfekt wäre zu übersetzen: »und du weißt (ja genau), was du zu tun hast «.

\subsection{2 wa-Perfekt zur Fortsetzung des Lang-Imperfekts}

Schließlich kann das Perf. cons. wohl auch - nachweisbar seit dem späteren 7. Jahrhundert - zur Fortführung des Lang-Imperfekts im nachzeitigen / futurischen Sinn gebraucht werden, so vielleicht zweimal in der Inschrift Nr. 5 aus H. Gazze / Horvat 'Uzzā: $:^{281}$

a) Der sehr fragmentarische Text beginnt mit einem doppelten Bedingungssatzgefüge - »wenn - wenn nicht« -, dem sich eine Serie von Ankündigungen

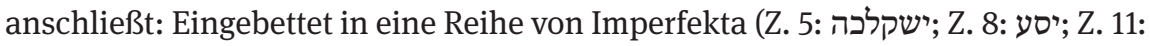
erscheint das Perf. cons. im Hitpalpel von der Wurzel ערמחל (ימחץ, masoretisch "und du wirst bloß gelegt werden«.

277 Dazu oben Kap. 4.1.2.1.

278 Die genaue Deutung - besonders von בצק - ist unsicher (Diskussion bei HAE I, 361 f.; HI, 17 f.; EP, 100 f.; vgl. Weippert, Textbuch, 358 Nr. 205); וצררת ist aber unbestritten Perf. cons. (vgl. Aharoni, Arad Inscriptions, 17; HAE I, 361 f.; HI, 16; 17 f.; Weippert, Textbuch, 358. - EP, 98 liest nur Imper. וצרר).

279 EP, 194-199. Zum Text siehe oben Kap. 4.2.1.1.

280 Vgl. die Passage in Z. 8 ff., dazu oben Kap. 4.2.1.1.

281 Beit-Arieh, Horvat 'Uza, 122-128 (Beit-Arieh; Cross); HI, 521-527; EP, 173-177; Renz, »Jahwe«: 347-349; 365 (vgl. zum Text auch ebd. 357-359), Literaturzusammenstellung ebd. 347 Anm. 443. 
- $\operatorname{Gaz}(7): 5 \mathrm{Z} .6-11^{282}$

\begin{tabular}{|c|c|}
\hline \multirow{2}{*}{$\begin{array}{r}{[. . . . .]^{5}} \\
{[\ldots]^{6}}\end{array}$} & \\
\hline & ... wird er/man dich wägen ... \\
\hline 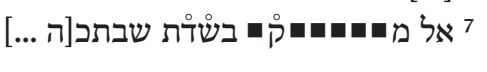 & $\mathrm{zu}[\ldots]$ (?) auf den Gefilden deines \\
\hline 8 ועללת יסע[...] & $\begin{array}{l}\text { Wohnens [...] } \\
\text { und Taten wird er/man (?) ausreißen }\end{array}$ \\
\hline 9 על פנ[יכה] והתערערתה [...] & und du wirst bloß gelegt werden ${ }^{283}$ \\
\hline 10 10 בדנ •[...] & (?) in Richtspruch \\
\hline 11 ימחץ [...]יכה בפלץ [...] & $\begin{array}{l}\text { er wird zerschlagen deine }[. . .] \\
\text { mit Schrecken/Schauer }\end{array}$ \\
\hline
\end{tabular}

b) Am Ende desselben Textes wird vielleicht nach einer Temporalbestimmung החר ימת מnach Tagen« ein Folgesatz mit Perf. cons. v. d. Wz. liert - der Kontext ist aber fragmentarisch.

- $\operatorname{Gaz}(7): 5$ Z. $12^{284}$

Nach Ablauf von Tagen wird/mag sein dein Grab im Fels (?)

c) Ein vom Antikenmarkt stammendes Ostrakon (»Silver, Pistachio and Grain «-Ostrakon) vom Ende des 7. / Beginn des 6. Jahrhunderts v. Chr. - vielleicht aus H. al-Kōm -, ein Palimpsest, ${ }^{285}$ lässt im zuerst geschriebenen, schwer lesbaren Text in Z. 10 noch die Verbalform ושלחתך וund ich werde dich schicken« sowie in Z. 12 die Form ועלה וund er wird hinaufziehen« erkennen. Ohne Kontext kann man beide Verbformen - vor allem die letzte, in der 3. Ps. formulierte - futurisch / nachzeitig verstehen.

$282 \mathrm{Zu}$ den verschiedenen Ergänzungsmöglichkeiten vgl. Beit-Arieh, Horvat 'Uza, 125 f.; HI, 524-526; EP, 176.

$283 E P, 174$ f. übersetzt vergangen: "and you have become destitute« - obwohl dies im futurischen Kontext, der auch von Ahituv nach Ausweis seiner sonstigen Übersetzung vorausgesetzt wird, eigentlich wenig Sinn macht.

284 Zur Lesung vgl. besonders André Lemaire, „Épigraphie palestinienne: Nouveaux documents II. Décennie 1985-1995, « Henoch 17 (1995): 209-242, 222 und EP, 174; 176.

285 Shmuel Ahituv und Ada Yardeni, »Silver, Pistachio and Grain. Two Letters Dealing with Deliverance of Silver and Products. An Ostracon of the Seventh-Sixth Centuries BCE, « in ZaphenathPaneah. Linguistic Studies Presented to Elisha Qimron on the Occasion of His Sixty-Fifth Birthday, Hg. Daniel Sivan, David Talshir, and Chaim Cohen (Beer-Sheva: Ben-Gurion University of the Negev Press, 2009): 15-28; EP, 199-205. 
Bei ושלחתךist allerdings auch einevorzeitige Deutung nicht auszuschließen: ${ }^{286}$ Man muss der angeredeten Person nicht ankündigen, dass man sie in der Zukunft schicken wird, sondern schickt sie sofort - terminiert für ein entsprechendes künftiges Datum.

Man hat bei diesen Beispielen eine der späteren Stufen der Einführung des Perf. cons. erreicht, wenn generell Nachzeitiges durch Perf. cons. fortgeführt werden kann. Freilich geht das, was in der hebräischen Bibel belegt ist, nochmals einen Schritt weiter. ${ }^{287}$

\subsubsection{Zum Vergleich: T. Dēr 'Allā und T. Dān}

Somit bleibt noch ein Seitenblick auf die südaramäischen Texte aus T. Dēr 'Allā und T. Dān, die beide anerkanntermaßen Narrative enthalten, ${ }^{288}$ denen aber auch wa-Perfekt gegenübersteht.

\subsubsection{T. Dēr 'Allā Verputzinschriften}

Nimmt man die Fragmentenzuordnung von André Lemaire u.a., neuerdings besonders von Erhard Blum, zum Ausgangspunkt, so zeigt auch die Kombination I der Inschriften von T. Dēr 'Alla ${ }^{289}$ zunächst im ersten, berichtenden Teil (Z. 1-6/7) eine Serie von $w a$-Kurz-Imperfekta / Narrativen als Haupterzähltempus in den Zeilen 2 bis 5; den Abschluss bildet die Redeeinleitung in Z. 5: ויאמר להם yund er (Bileam) sprach zu ihnen«.

286 Dazu oben Kap. 4.1.2.4.

287 Dazu unten Kap. 5.2.

288 Dazu oben Kap. 3.2.1 Abschn. 3.

289 Zum Text vgl. nach der Erstedition Jean Hoftijzer und Gerrit van der Kooij, Aramaic Texts from Deir 'Alla (Leiden: Brill, 1976), zur Stelle: 173; 179; 192 f., bes. Helga und Manfred Weippert, »Die >Bileam<-Inschrift von Tell Deir 'Alla, « ZDPV 98 (1982): 77-103; Manfred Weippert, »The Balaam Text from Deir 'Alla and the Study of the Old Testament, « in The Balaam Text from Deir 'Alla Re-evaluated, Hg. Jean Hoftijzer und Gerrit van der Kooij (Leiden u. a.: Brill, 1991): 151-184; Erhard Blum, »Die Kombination I der Wandinschriften vom Tell Deir 'Alla. Vorschläge zur Rekonstruktion mit historisch-kritischen Anmerkungen, « in Berührungspunkte. Studien zur Sozial- und Religionsgeschichte Israels und seiner Umwelt. Festschrift für Rainer Albertz zu seinem 65. Geburtstag, Hg. Ingo Kottsieper u. a., AOAT 350 (Münster: Ugarit-Verlag, 2008): 573-601 sowie die Textsammlungen TUAT II 138-148 (Hoftijzer); CoS 2, 140-145 (Levine); EP, 433-465; KAI', 312; TUAT.NF 8, 461-469 (Blum). - Zu Sprache und Syntax vgl. zudem bes. Müller, »Sprache«: 11-19; Tropper, Zincirli, 301-306; Schüle, Syntax, 134 f.; 110 u.ö.; Blum, »Verbalsystem«: 125 sowie die Beiträge in: Jean Hoftijzer und Gerrit van der Kooij, Hg. The Balaam Text from Deir 'Alla Reevaluated (Leiden u. a.: Brill, 1991). 
Die Rede Bileams, die den Inhalt seiner vorher in Z. 1-2 angesprochenen Vision beinhaltet, setzt in Z. 5 ein - im Parallelismus formuliert: ${ }^{290}$

Setzt euch! Ich will euch mitteilen, was die Schadayin-Gott[heiten beraten haben]. ${ }^{291}$ \|

Und auf (geht)! Seht das Tun der Götter!

Schadayin-Gottheiten (שדין) und Götter (אלהן) sind im Parallelismus erkennbar synonym gebraucht ${ }^{292}$ - und auch im Folgenden demnach so zu verstehen.

Die Rede fährt dann in Z. 5 f. - ebenfalls parallel - fort:

Die Götter versammelten sich \|

und es standen die Schadayin-Gottheiten in der / als Versammlung.

Und sie sagten zur Sonnengöttin:293

Es folgt die wörtliche Rede der Götter zur Sonnengöttin.

Auffällig und immer wieder als anstößig empfunden folgt auf ein syntaktisch verständliches $x$-qatal am Abschnittsanfang in Z. 5 (אלהן אתיחדו [Perf. Itp. von zweimal wa-qatal(-x) in Erstposition in Z. 6 (יחד [wa-Perf. N-Stamm von

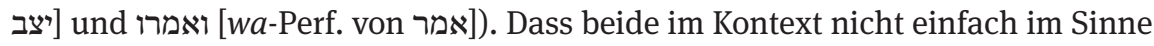
eines Narrativs übersetzt werden dürften, ist naheliegend. So wurden beide waPerfekta im Sinne des biblisch-hebräischen Perf. cons. und damit letztlich als Alloform zum Lang-Imperfekt verstanden, in dem Sinne, dass eine begleitende Hintergrundinformation gegeben würde. ${ }^{294}$ Die Übersetzung lautete konsequenterweise: »indem die Schadayin-Gottheiten in der Versammlung aufstanden und sagten«. Die Hauptebene der Erzählung innerhalb der Rede würde sich damit auf אלהן אתיחדו die Götter versammelten sich« beschränken, der Rest würde der

290 Zur Rekonstruktion vgl. Weippert, »Balaam Text«: 154; 156; CoS 2, 142 (Levine); EP, 435-439; Blum, »Kombination I«: 577 und bes. TUAT.NF 8, $466 \mathrm{f}$.

291 Alternative Ergänzung: »tun werden«.

292 Dabei kann dann offen bleiben, wie die šdyn sprachlich und religionsgeschichtlich herzuleiten sind; dazu ausführlich zur Stelle Weippert, »Inschrift«: 88-92 (Lit). - Früher war statt שדין der Gottesname Šgr gelesen worden (vgl. Hoftijzer und van der Kooij, Aramaic Texts, 173; Weippert, »Inschrift«: 83).

293 Auch hier war früher Šgr gelesen worden.

294 So neben anderen Weippert, »Inschrift«: 88; Blum, »Kombination I«: 577 und ders., »Verbalsystem «: $125 \mathrm{f}$. Auch der Ansatz von Schüle, Syntax, 134-136 im Rahmen der Erwägungen (ebd. 120-132), solche Perf. als tempusneutrale Stative, die neben der Voraussetzung und Folge eines Zustandes auch die Neben- und Begleitumstände der eigentlichen Hauptaussage bezeichnen können, geht letztlich in dieselbe Richtung, vermeidet allerdings die vorschnelle Korrelation mit dem spezifisch biblisch-hebräischen Perf. cons. 
Nebenebene zugeordnet. Dies war umso leichter möglich, als statt שדין an zwei אלהן Stellen der Göttername Šgr gelesen wurde und damit keine Parallelität von und שדין vorlag. Man konnte sogar in V. 5 f. die Schadayin als möglicherweise rebellierende Untergruppe von den eigentlichen Gottheiten abtrennen; deren Handeln wäre dann ein Nebenaspekt der eigentlichen Götterversammlung. ${ }^{295}$ Die Lesung שד]ין in V. 5 erlaubt dies nicht mehr. Zudem sind die beiden Aussagepaare in V. $5 \mathrm{f}$. nicht nur parallel formuliert, sondern auch durch chiastischen Aufbau inhaltlich aufeinander bezogen: ${ }^{296}$ als zwei Teilaussagen derselben Gesamtaussage: Das Versammeln der Götter (אלהן) und das sich Hinstellen der SchadayinGottheiten stehen beide auf derselben Ebene - der Hauptebene der wörtlichen Rede. Damit ist nicht mehr das wa-qatal als Nebenaspekt des $x$-qatal aufzufassen; eine Deutung im Sinne eines mit einem Lang-Imperfekt quasi funktionsgleichen Perf. cons. bereitet Schwierigkeiten. Am leichtesten ist die Verb-Position durch die vom Chiasmus vorgegebene Satzstellung zu erklären - wie ja auch im Ugaritischen stilistische Gründe für die Tempuswahl mitentscheidend sind. ${ }^{297}$ Perfekt wäre perfektiv-vergangen, wa- einfache copulative Konjunktion. ${ }^{298}$

Das folgende wa-Perfekt ואמרו führt die Aussage weiter. Hier kann erst recht nicht von einer Nebenaussage auf der Hintergrundebene gesprochen werden. ואמרו setzt in der aktuellen Textlesung nicht nur das Handeln der SchadayinGottheiten fort - die man als Nebenebene charakterisieren könnte -, vielmehr führt ואמרו beide chiastisch verbundenen und inhaltlich identischen vorhergehenden Aussagen fort: Götter und Schadayin sind identisch; die Aussage wird mit ואמרו auf der Hauptebene weitergeführt. Auf die im Folgenden zitierte Rede der Gottheiten und deren Einführung durch ואמרו läuft der ganze Bericht der Z. 1-6 hinaus. Am leichtesten könnte man wa-Perfekt hier als retardierenden Neueinsatz innerhalb des Berichts - durch vorzeitig zu verstehendes Perfekt von der Erzählerperspektive aus gesehen - interpretieren. ${ }^{299}$

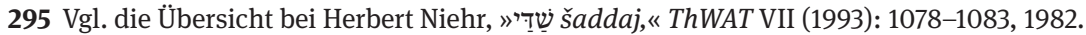

296 Bereits angedeutet u. a. bei Weippert, »Balaam Text«: 156 Anm. 20; dann Blum, TUAT.NF 8, 467 Anm. 36.

297 Dazu oben Kap. 2.1.1.

298 Eine Deutung von wa-qatal als Stativ, um die Problematik eines wa-copulativum mit Perf. zu umgehen (im Anschluss an Schüle, Syntax, 134-136; s. o.), verändert nicht viel: Beide Aussagen sollten wegen des chiastischen Parallelismus auf derselben Ebene bleiben, wa-qatal ונצבו stellt keine Hintergrundebene zur Hauptebene dar.

299 Angedeutet wird dies in der neuesten Übersetzung Erhard Blums: Nach der betonten Deutung der einschlägigen Stellen innerhalb der Kombination I als Umstandssätze im Rahmen der Inversionsregeln des Biblisch-Hebräischen (Blum, »Verbalsystem«: $125 \mathrm{f}$.) und der Übersetzung: »Die Götter versammelten sich; dabei standen die Schaddajin in der Versammlung und sprachen ...« (Blum, »Kombination I«: 577; Hervorhebung von mir) lautet die neueste Übersetzung 
Wahrscheinlich kann also auch aus dem vorliegenden Text nicht geschlossen werden, dass das wa-Perfekt exakt die Funktion des hebräischen Perf. cons. innehatte - im Sinne eines Tempus, das als Äquivalent, ja Alloform zum Lang-Imperfekt angesehen werden kann, mithin, ob ein System mit zwei konsequent unterschiedenen Inversionspaaren vorausgesetzt werden muss. Schon die Sprache Aramäisch rät dazu, die südaramäischen Inschriften nicht völlig von der aramäischen Sprachentwicklung abgekoppelt zu betrachten: Man müsste sehr mutig sein, zu postulieren, dass dieser südaramäische Dialekt, anders als alle übrigen älteren und späteren aramäischen Dialekte, kein durch wa- angereihtes Perfekt als Erzähltempus besessen haben soll: Die Inschrift von $\bar{A}$ fis jedenfalls, einer der weiteren Belege für die Existenz eines Narrativs, ${ }^{300}$ kennt daneben selbstverständlich satzeinleitendes wa-Perfekt als Erzähltempus. Die bloße Existenz eines Narrativs kann ja nicht gleichzeitig als Hinweis auf die Existenz der gesamten Inversionspaare qatal \| wa-yaqtul (KF) und yaqtulu (LF) \| wa-qatal gelten.

Nicht nur das Ugaritische, auch das Phönizische, Sam'alische und andere Sprachen kennen ja zumindest das Nebeneinander von erzählendem wa-Perfekt und wa-Perfekt im nachzeitigen Sinne im Nachsatz von Bedingungs- und Temporalsätzen.

Im späteren Verlauf des dann nicht mehr so sicher rekonstruierbaren Textes wechseln Perfekta und Lang-Imperfekta nochmals.

In abgebrochenem Kontext erscheint zudem in Z. 3 f., durch Konj. wa- angeschlossen, das durch Inf. abs. verstärkte Lang-Ipf. יבכה in der Wendung: ובכה יבכה וund er weinte dabei

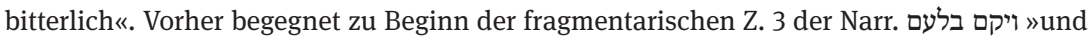
Bileam stand auf«; unmittelbar vor ובליכ] ל könnte ובכה יבכה "und er konnte nicht" gestan-

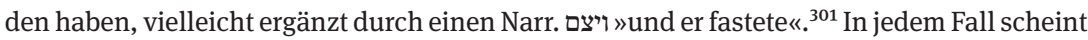
das erweiterte und durch $w a$ - angeschlossene Lang-Ipf. in Gestalt der Konstruktion $w a-x$ yaqtulu eine Berichtskette zu unterbrechen: יבכה dürfte somit am ehesten Gleichzeitiges / Parallellaufendes, in der Sache auch Durativisches bezeichnen - vergleichbar vielleicht der Verwendung des Lang-Ipf. in der T. Dān-Inschrift. ${ }^{302}$ Diese Wendung bewegt sich damit völlig im Rahmen des imperfektiven / gleichzeitig-nachzeitigen Lang-Ipf. nordwestsemitischer Texte. Rückschlüsse auf die Bedeutung des ebenso nachgestellt eine Berichtskette unterbrechenden wa-Perfekt in Z. 5 f. sind daraus aber nicht zu ziehen. Dass wa-x-yaqtulu funktionsidentisch mit wa-qatal ist, ist jenseits des Klassisch-Biblisch-Hebräischen ja nicht automatisch zu veranschlagen.

der letzten Verbalform - inhaltlich, stilistisch und von der Textstruktur her sicher am geeignetsten - unter Abtrennung mit neuem Satzanfang: »Und sie sagten ...«(Blum, TUAT.NF 8, 467). Vergleichbar EP, 438 f.; $\operatorname{CoS}$ 2, 142; bereits Hoftijzer und van der Kooij, Aramaic Texts, 179; 298. 300 Dazu oben Kap. 2.2.3 Abschn. 2.

301 So etwa Weippert, »Balaam Text«: 154; Blum, »Kombination I«: 577.

302 Schüle, Syntax, 110 verweist zu Recht darauf, dass zudem eine Begleithandlung außerhalb der Haupterzählungsebene angesprochen ist. 


\subsubsection{T. Dān Steininschrift}

Dass die ebenfalls südaramäische T. Dān-Inschrift im Hauptgerüst den hebräischen Narrativen entsprechende Kurz-Imperfekta in Kombination mit der Konjunktion wa- kennt, ist von Anfang an aufgefallen. ${ }^{303}$

- T. Dān Z. 3-9

$$
\begin{aligned}
& \text { 3ויעל ... } \\
& \text { 6ואקתל מל[כ]ז [רב]בן ... }
\end{aligned}
$$

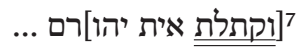

$$
\begin{aligned}
& \text { 8מלך ישראל אית יותית } \\
& \text { וקתל]ת אית אחז]יהו ... } \\
& \text { [מל] }
\end{aligned}
$$

und er drang ein ... und er machte zum König ... und er ging ... und ich zog aus und ich tötete zahlreiche Könige ... - und zwar tötete ich den Joram ..., den König von Israel, und tötete den Ahas ..., den König von Bet Dawid und ich setzte / machte ...

Wenn in Z. 7 und sicher in Z. 8 die im Narrativ berichtete Tötung von Königen aus Z. 6 exemplifiziert wird, indem Joram von Israel und wohl Ahas von Juda ausdrücklich genannt werden, geschieht dies mit durch $w a$ - angereihte Perfekta: und damit T. Dēr 'Allä Kombination I vergleichbar. Auch hier ist nicht von vornherein mit einem dem biblisch-hebräischen Perf. cons. entsprechenden Tempus im Sinne einer Alloform zu imperfektivem Lang-Imperfekt zu rechnen: Es geht nicht um einen gleichzeitig im Hintergrund ablaufenden Vorgang - zu übersetzen mit: »Ich tötete zahlreiche Könige, während ich Joram ... und Ahas ... tötete«. Ein Progress ist allerdings ebenfalls nicht gemeint. Die Textstruktur soweit sie erkennbar ist - legt eine Spezifizierung der vorher im Narrativ angesprochenen Tötung einer größeren Zahl von Königen nahe. wa-Perfekt dürfte damit die Funktion eines retardierenden Neueinsetzens aus der Gegenwartsperspektive des Berichtenden heraus übernehmen - herkömmlich gerne als konstatierendes Perfekt bezeichnet. In jedem Fall würde wa-Perfekt den Erzählfluss, den Progress unterbrechen - ohnehin eine der Funktionen des Perfekts. ${ }^{304}$

303 Siehe dazu auch oben Kap. 3.2.1 Abschn. 3. - Biran und Naveh, »Stele Fragment«: 81-98; dies., »New Fragment«: 1-18; André Lemaire, »The Tel Dan Stela as a Piece of Royal Historiography, « JSOT 81 (1998): 3-14; Siegfried Mittmann, »Zwei >Rätsel der Mẹ̄ša'-Inschrift, « ZDPV 118 (2002): 33-65 (Lit.); Kottsieper, »Aspekte«: 60-62; 70-72; Athas, Inscription (Lit.); EP, 464-473 (Lit.); Weippert, Textbuch, 267-269 Nr. 116 (Lit.).

304 Die beiden in der Inschrift vorkommenden Ipf. יהך in Z. 3 und יסק in Z. 2 ohne vorangehende Konj. wa- dürften der jeweils vorangehenden Verbform zugeordnet sein, ohne dass verlässlich gesagt werden kann, ob Lang- (gleichzeitig? final?) oder Kurz-Ipf. vorliegt. In jedem Fall können diese Formen nicht automatisch als funktionsgleich mit den wa-Perf.-Formen וקתלת aufgefasst werden und zur gegenseitigen Erklärung herangezogen werden. Zur Diskussion vgl. u. a. Trop- 
Die Zakkur-Inschrift von $\bar{A} f i s$ bezeugt jedenfalls das problemlose Nebeneinander von Narrativen / wa-Kurz-Imperfekta und wa-Perfekt als Berichts-Tempus der Vergangenheit. ${ }^{305}$

\section{Ergebnisse}

\subsection{Das biblisch-hebräische »Normalsystem« - seine Entstehungssituation}

Geht man nun zum Abschluss auf das eingangs angeführte lehrbuchhafte biblisch-hebräische Normalsystem zurück, so geht es hier nicht um eine - von Zeit zu Zeit in Mode geratene - Bestreitung dieses Systems, das zu einer bestimmten Zeit in einem bestimmten Corpus - eben literarischer Prosa - existiert hat, wenn auch nicht alle Belege widerspruchsfrei oder zumindest ohne gewaltsamere Deutungen eingebaut werden können.

Es sollte vielmehr um die Frage der Gültigkeitsdauer bzw. um den Beginn dieses Systems gehen. Das recht künstlich wirkende System klassischer hebräischer Tempuslehre mit seinen Inversionspaaren muss ja irgendwann entstanden sein.

Jedes Modell, das versucht, alle, auch die außerbiblischen Texte, aus dem klassischen System heraus zu erklären - mit dem Argument, dass sonst Doppelungen und Uneindeutigkeiten entstünden -, muss das Problem ausklammern, dass es in jedem Fall eine Zeit gegeben haben muss, in der Elemente des alten Systems, wie man es seit Ugarit kennt, neben den Neuerungen des biblisch-hebräisch Belegten existiert haben: Man darf ja historisch nicht erwarten, dass zu einem bestimmten Zeitpunkt quasi durch Urknall die perfektiv-vorzeitige Funktion von wa-Perfekt abgeschafft und die des Perf. cons. eingeführt wurde. Die unterschiedliche Verwendung der Perfekta lässt sich auch - anders als die Reduktion des präteritalen Kurz-Imperfekts auf die Kombination wayyiqtol - nicht durch phonetische Veränderungen wie den Wegfall der kurzen Endvokale zu Beginn der Eisenzeit erklären. ${ }^{306}$ Nicht einmal diese Reduktion des Kurz-Imperfekts auf den Narrativ ist ja konsequent vollzogen, wie Personennamen und Poesie zeigen. Analog hätte zu einem festen Zeitpunkt die Umstellung vom Lang-Imperfekt zum Partizipialsatz zur Darstellung der Gleichzeitigkeit vollzogen worden sein müssen.

per, »wyqtl«: 640-643 (auch ältere Darstellungen des Vf.s zusammenfassend); Mittmann, »Rätsel«: 48 f.; Schüle, Syntax, 201-203; Kottsieper, »Aspekte«: 60-62; 70-72; Gzella, Tempus, 323. 305 Dazu oben Kap. 2.2.3 Abschn. 2.

306 Schüle, Syntax, 127-139 und ff. versucht, durch die Einführung des extemporalen Stativs neben dem perfektiv-vorzeitigen Perf. tatsächlich zwei unterschiedliche Tempora einzuführen. 
Die hier interessierende Frage ist, wann diese Übergangszeit anzusetzen ist, und ob nicht gerade in den hebräischen Inschriften dieser Übergang noch erkennbar ist.

\subsection{Die Entwicklung hin zum Perfectum consecutivum}

Die Entwicklung zum Perf. cons. könnte demnach an der Oberfläche so aussehen, dass auf die erste Verwendung der noch keineswegs verbindlichen, aber häufigen Abfolge von wa- und Perfekt zur Benennung von Nachzeitig-Fortführendem a) im Nachsatz von Bedingungssätzen und Vergleichbarem (seit dem Ugaritischen und Amarna-Kanaanäischen auch in vorwiegend kanaanäischen Sprachen der Eisenzeit, daneben im Klassisch-Arabischen sowie in äthiopischen Dialekten ${ }^{307}$ ) und b) nach auslösenden Modi zur Bezeichnung von Final- und Konsekutivsätzen (erst im Amarna-Kanaanäischen) dieselben Funktionen auch im InschriftlichHebräischen belegt sind. Hinzu kommt inschriftlich-hebräisch dann neu die Fortführung volitiver Modi nicht nur in finalem Sinne, sondern als eigentliche Fortsetzung des Befehls durch weitere Anordnungen - dies offenbar ohne Vorläufer und Parallelen. Die nordwestsemitisch - und darüber hinaus - häufige Verwendung der Konj. wa- - als sogenanntes wa-apodoseos oder auch wa-explicativum - zur Einleitung jeder Art von Folgesätzen spielt in diesem Zusammenhang eine wesentliche Rolle. ${ }^{308}$

307 Zum Arabischen vgl. Brockelmann, Grammatik, § 155, zum Äthiopischen z. B. Ewald Wagner, »Das Verb im alten und modernen Harari, « in Tempus und Aspekt: 159-169, 161.

308 Dazu bes. Joüon und Muraoka, Grammar, §176; Hans-Peter Müller, »Nicht-junktiver Gebrauch von $w$ - im Althebräischen, « ZAH 7 (1994): 141-174, 162 f. und ff.; $U G \S 83.113$; 83.114; CAT 3, 102-108 (auch zu akkadischen Regionaldialekten); vgl. Waltke und O’Connor, Syntax, 521 f.; Smith, Origins, 8; Schüle, Syntax, 133 f.; 135 u.ö. - Inschriftlich-Hebräisch findet sich möglicherweise im Lachisch-Brief Lak(6):1.3 Z. 10-13 die Einleitung eines Nachsatzes mit Ipf. und wa-apodoseos: וגם כל ספר אשר יבא אלי | אם קראתי אתה | ואחר אתננהו אל מאומה וund auch jeden Brief (Casus pendens), der zu mir kommt, wenn ich ihn gelesen habe, so kann ich ihn nachher bis ins Detail wiederholen« (HAE I, 417 f.; bes. 414-416 [Lit.]; HI, 309; 312; vgl. EP, 63 zu Z.12 mit Neueinsatz: »And furthermore [ועוד], I will grant it as nothing«). - Dem wa-apodoseos vergleichbare Konstruktionen finden sich auch im arabischen Sprachraum und im Äthiopischen (vgl. die Übersichten Moran, »Byblos«: 72, Anm. 199; CAT 2, 102-104; Waltke und O’Connor, Syntax, 521 f.). Vgl. speziell zum Sabäischen ( $f a$-) Maria Höfner, Altsüdarabische Grammatik, POL 24 (Leipzig: Harrassowitz, 1943), 171; 185 (§ 142); Stein, Lehrbuch, 110 (»Progreßpartikel«), zum Äthiopischen August Dillmann, Grammatik der äthiopischen Sprache (Leipzig: Weigel, 1857), 426-429; Josef Tropper, Altäthiopisch, ELO 2 (Münster: Ugarit-Verlag, 2002), § 65.6, zum Klassisch-Arabischen Brockelmann, Grammatik, § 155. 
Es muss hier nicht weiter interessieren, wie das Perf. in Bedingungssatzgefüge Eingang fand $^{309}$ - die Frage ist immer wieder diskutiert worden. So könnte die Entstehung auch gleich- und nachzeitiger Bedeutungen für das Perf. (SK) - gerade auch des Perf. cons. a) aus der Bedeutung eines ursprünglich extemporalen Stativs (aus dem erst später nordwestsemitisch ein perfektiv-vorzeitiges Perf. wurde) erklärt werden, ${ }^{310}$ wenn man nicht b) die volitive Bedeutung des (perfektiv verstandenen) Perf. zum Ausgangspunkt der Erklärung nimmt ${ }^{311}$ oder c) generell alle Erscheinungsformen des Perf. aus dem Aspekt "perfektiv « heraus erklärt. ${ }^{312}$ Die inschriftlich-hebräischen Belege beziehen sich auf fientische, oft sogar transitive Verben. ${ }^{313}$ Eine unmittelbare Ableitung von einem (extemporalen) Stativ ist somit nicht möglich. ${ }^{314}$

309 Vgl. die Übersichten bei Smith, Origins, 1-15, speziell 13-15; Waltke und O'Connor, Syntax, 458-478; 521-526.

310 Neuerdings bes. Schüle, Syntax, 127-132, konkret 133-139; vgl. Wolfram von Soden, »Gab es bereits im vorexilischen Hebräisch Aramaismen in der Bildung und der Verwendung von Verbalformen?, «ZAH 4 (1991): 32-45, 36-43 (»habitativ«). Bereits ursemitisch nimmt besonders Rainer Voigt zwei unterschiedliche Afformativkonjugationen an: 1) Einen Stativ von Zustandsverben, gegebenenfalls auch intransitiven Verben, und 2) ein aktives Perf. (Rainer Voigt, »Die beiden Suffixkonjugationen des Semitischen, «ZAH 15/16 [2003/2004]: 138-165).

311 Meyer, Grammatik, § 101 S. 53 Anm. 4; Müller, »Imperfectum consecutivum «: 157-159; neuerdings auch Joosten, System, $262 \mathrm{f}$.; $289 \mathrm{f}$.

312 So im Gefolge Carl Brockelmanns (z. B. ders., Syntax, § 41f.) u. a. Tropper, »Aspektsystem «: 181-186. William L. Moran geht noch weiter, wenn er Perf. sehr allgemein als »tenseless aorist « (Moran, »Byblos«: 35; vgl. 33-38) definiert. Zu unspezifische Bestimmungen, die alle Belege unter eine möglichst allgemeine Definition subsumieren, passen zwar überall, lassen aber umgekehrt nicht mehr erkennen, weshalb gerade ein spezifisches Tempus gewählt wurde; die Aussage wird uneindeutig. Zumindest für das Biblisch-Hebräische dürfte innerhalb des Systems der Inversionspaare die Verwendung des Perf. cons. zur Fortführung nachzeitiger, iterativischer (/ durativischer) und genereller Sachverhalte nachweisbar sein.

313 Belege aus Kap. 4.1 bis 4.2: 1. Nachsatz im Bedingungssatz: נתן (KAgr[9]:10, 2-3); ?חה (2) (Nim[8]:1, 3). - 2. In vergangenem Sinne: צוה Pi. (Arad[6]:3, 3; pltyhw-Ostrakon 3); שלח ? בלח (King) (Arad[6]:16, 4; evt. »Silver, Pistachio and Grain«-Ostrakon 10); ברך Hif. (edomitisch H. Ġazze); evt. אסם (MHas[7]:1). - 3. Nachsatz nach Befehl: Transitiv: לקח (Arad[6]:3, 6-8; Arad[6]:17, 1-4); רעה ([?] Mur[7]:1, 4); כתב (Arad[6]:7, 6); נתר (Aerforschen« (»Nôqĕdîm«-Ostrakon); שמע ([?] MHas[7]:1, 14); פקד Hif. $(\operatorname{Arad}[6]: 24,13-16) ;$ נתן (Arad[6]:2, 7 f.); צר i.S. v. »beladen« (Arad[6]:3, 5f.); ידע (»Nôqĕdîm«Ostrakon 7 f.). - Aktive Stammesmodifikation eines Zustandsverbs: סבב Hif. (Arad[6]:2,5f.). Abgeleitete Stammesmodifikationen intransitiver, aber fientischer Verben: יעד Dif. "sich treffen" (»Nôqĕdîm«-Ostrakon); ערער Hitpalpel »bloß gelegt werden« (Gaz[7]:5, 9). - Intransitiv: עלה (evt. ״Silver, Pistachio and Grain«-Ostrakon 12). - והיה (Gaz[7]:5, 12).

314 Schüle, Syntax, 127 f. und ff. vermutet deshalb Reste eines stativischen Gebrauchs auch für fientische, transitive Verben; anders offenbar Voigt, "Suffixkonjugationen «: passim, der zwischen aktiven Perf. transitiver, fientischer Verben einerseits und Stativa intransitiver Verben oder Zustandsverben andererseits unterscheidet. 
Für die vorliegende Fragestellung ist ebenfalls von geringerer Bedeutung, ob man, wie vorgeschlagen, das, was herkömmlich und neuerdings ebenso in linguistisch-synchronen Analysen als Perf. cons. zusammengefasst wird - also eine Alloform zum Lang-Ipf. -, nochmals aufteilen soll, in a) echtes Perf. cons., das ein nachzeitiges Tempus weiterführt, und in b) ein habitatives, vom Stativ herkommendes »Perf. copulativum « ${ }^{315}$ für iterativisch / durativische, speziell auch intendierte Sachverhalte. ${ }^{316}$

Daneben kennen die Inschriften - nicht nur die hebräischen - auch noch die Abfolge wa-Perfekt zur Darstellung von Perfektivem / Vorzeitigem, a) zur Einleitung neuer Themen in Berichten, b) zur Reliefgebung, vielleicht auch c) als Abschluss einer Narrativkette.

Für die historische Einordnung von Bedeutung ist die Tatsache, dass es nicht um die Verwendung eines narrativen Perfekts mit wa-copulativum (Perfectum copulativum) geht; die hier aufgeführten Stellen stehen allesamt nicht als Ersatz für wayyiqtol als Erzähltempus. ${ }^{317} \mathrm{Im}$ Gegenteil sind demgegenüber die wenigen Narrativbelege der Inschriften wohl tatsächlich auf den Progress spezialisiert.

Diese Entwicklung hin zum Ersatz der Narrative durch Perfekt mit wa-copulativum dürfte tatsächlich erst dem späteren Hebräisch, wie es außerhalb der Hebräischen Bibel etwa in der Mischna erkennbar wird, vorbehalten sein. Die einschlägigen Grammatiken zum Mittelhebräischen machten dies seit jeher deutlich. ${ }^{318}$ Auch rückblickend, vom Mittelhebräischen aus betrachtet, ist damit nicht automatisch jedes Perfekt mit der Konjunktion $w^{e}$ - automatisch verdächtig, spät zu sein. Es geht um ein wa-qatal, das ähnlich wie das im klassischen System theoretisch ausschließlich erlaubte wa-x-qatal verwendet wird.

Am Ende der vorexilisch nachweisbaren Inschriften steht schließlich ein System, das die Folge $w a$-Perfekt dann generell auch zur Fortführung von LangImperfekta - über einzelne Vorläufer hinaus nicht nur im Nachsatz von Bedin-

315 Der Begriff wäre in jedem Fall zu vermeiden, da er mit vorzeitigem perfektivem Perf., das mit wa-copulativum angereiht wird, verwechselt werden könnte.

316 So von Soden, »Aramaismen«: 36-43; sachlich darauf aufbauend, aber anders Schüle, Syntax, 127-132. Die materielle Basis und den Ausgangspunkt der Diskussion bietet in jedem Fall Spieckermann, Juda, 120-130.

317 Vgl. auch die Diskussion zu II Reg 23 bei Pietsch, »Tempus«: 161-169; 177.

318 Dazu Karl Albrecht, Neuhebräische Grammatik auf Grund der Mišna, Clavis Linguarum Semiticarum V (München: Beck, 1913), § 104-107; Moses H. Segal, Mishnaic Hebrew (Oxford: Clarendon, 1927), § 306-350; Meyer, Grammatik, § 102,7a-b, zusammenfassend auch Smith, Origins, 59-63 u.ö. Ein ähnliches System ist auch in den älteren mittelhebräischen Inschriften vorauszusetzen, dazu Beate Ridzewski, Neuhebräische Grammatik auf Grund der ältesten Handschriften und Inschriften, Heidelberger orientalistische Studien 21 (Frankfurt u. a.: Peter Lang, 1993), 160-165. 
gungssatzgefügen ${ }^{319}$ - kennt - also ein Tempus, das man nun als Perfectum consecutivum bezeichnen kann. Dieses System erscheint im Biblisch-Hebräischen

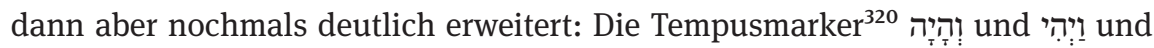
die auffällig häufige, ja systematische Verwendung des Perf. cons. - als Äquivalent zu jeder Form des Gleich- und Nachzeitigen (einschließlich Partitipialkonstruktionen wie Futurum instans), Volitiven und (Durativisch /) Iterativischen ${ }^{321}$ fehlen inschriftlich noch. ${ }^{322}$ Generell scheinen auch die Setzung von vorzeitigem Perfekt und Narrativ oder die Gliederung von narrativen Texten durch andere Tempora noch freier gewesen zu sein. ${ }^{323}$

Das Ende der vorexilischen Zeit könnte so in mehrerlei Hinsicht dem nahekommen, was als klassisches Hebräisch gilt: Die häufigere Verwendung des Partizipialsatzes, wa-qatal im Sinne des klassischen Perfectum consecutivum. Dazu kommt, dass erst einige späte Arad-Ostraka - besonders Nr. 24 - auch in der Orthographie mit Pleneschreibung langer Vokale im Wortinnern dem biblischen Hebräisch nahekommen. Ein konsequent-symmetrisches System von Inversionspaaren mit Ausschluss bestimmter Kombinationen von Satzposition, Konjunktion wa- und Tempusmorphem ist inschriftlich-hebräisch aber nie erreicht. $^{324}$

Auffällig bleibt, dass dieses biblisch-hebräische System seinen literarischen Höhepunkt und seine volle Ausprägung vielleicht in der Zeit hatte, als das He-

319 Dies ist schon im Amarna-Kanaanäischen (Kap. 2.1.2.4) und Phönizischen (Kap. 2.2.2.3) angedeutet.

320 Vgl. dazu auch Schüle, Syntax, 182-186. Vorläufer mögen die Verzeitungen von Partizipien und Nominalsätzen durch das Verbum »sein« im Phönizischen, Aramäischen und Althebräischen sein.

$321 \mathrm{Zu}$ den Verwendungsweisen vgl. neben den einschlägigen Grammatiken auch Blum, »Verbalsystem «: 122 ff. u.ö.

322 Die gezeigte breite Verwendung von wa-Perf. zur Fortsetzung - später vielleicht sogar generell zur Realisierung - von imperfektivischen Sachverhalten spricht dagegen, wie vorgeschlagen (Ola Wikander, »The Hebrew Consecutive Wāw as a North West Semitic 〉Augmentı: A Typological Comparison with Indo-European, « in VT 60 [2010]: 260-270) dem wa- der Konsekutivtempora eine reine Temporalisierungsfunktion - ausdrücklich ohne Progresscharakter - der sonst atemporalen Aspektformen Ipf. und Perf. im Sinne indoeuropäischer Augmenttempora zuzuweisen. Zumindest $w a$-Perf. ist genauso wenig temporal festgelegt im Sinne eines absoluten Tempussystems wie einfaches Lang-Ipf. und keineswegs primär auf die Zukunft festgelegt (so ebd., 268 f.). Dass an der Oberfläche funktionale Ähnlichkeiten zumindest des $w a$-Kurz-Ipf. mit den Augmenttempora des Indoeuropäischen bestehen, soll nicht bestritten werden.

323 Dazu oben Kap. 3.

324 Das Gezeigte dürfte dann, wenn man das bekannte geschlossene System von Inversionspaaren (s. o. Kap. 1.1) nicht voraussetzen kann, auch Auswirkungen für die Deutung von - theoretisch unerlaubtem - Lang-Ipf. mit wa-copulativum haben. 
bräische als Verwaltungssprache durch das Aramäische ersetzt war. ${ }^{325}$ Jedenfalls existierte es grundsätzlich weiter bis in die Zeit der Qumrantexte. ${ }^{326}$

\subsection{Faktoren der Tempuswahl - "Sprachökonomie»}

Ebenfalls unter Rückgriff auf das zu Anfang Angedeutete legt gerade auch die Sprache der hebräischen Inschriften - im Kontext anderer nordwestsemitischer Texte - nahe, zu einer Spracherklärung zu greifen, die nicht nur Aspekt, Tempus und Modus, sondern mehrere Faktoren bei der Tempuswahl kennt, darunter Stilistik, Reliefgebung, feste Verwendungsweisen wie die Konstruktion von Bedingungssätzen, die Konstruktion von Beginn (Neueinsatz) oder Abschluss einer Erzählsequenz, aber auch die unterschiedliche Konstruktion unterschiedlicher Sachverhalte, verschiedene Sprachebenen, Textpragmatik, Sprach- bzw. Literaturgattungen usw. Die tatsächlich synchron realisierten Verwendungen der Tempora raten auch zur Vorsicht, ein gar zu festes System zu unterstellen, das im Sinne einer modern gedachten Sprachökonomie systematisiert ist.

Dass Derartiges trotzdem verstanden wurde, zeigt am besten die Tatsache, dass ein großer Teil der hebräisch-epigraphischen Briefe und Urkunden wie auch die kanaanäischen Amarna-Texte aus dem Bereich der Militärverwaltung kommen; die rückblickend formulie-

325 Damit wird man das Perf. cons. wohl kaum als Erfindung der biblischen Redaktoren ansehen dürfen (so Rüdiger Bartelmus, »'Revitalisierung des Althebräischen` oder: Kann man ein Konstrukt neu beleben, indem man ein neues Konstrukt schafft?, " in Mein Haus wird ein Bethaus für alle Völker genannt werden (Jes 56,7). Festschrift für Thomas Willi zum 65. Geburtstag, Hg. Julia Männchen (Neukirchen-Vluyn: Neukirchener, 2007): 405-422, 422); die konsequente Ausprägung des symmetrischen Tempus-Systems könnte aber durchaus in die Zeit einer primär literarischen Beschäftigung mit hebr. Texten anzusetzen sein (tendenziell ähnlich Smith, Origins, 13-15). Mit der Systematik des bibl.-hebr. Systems und dessen Narrativen als Erzählbasis erklärt auch Gzella, Tempus, 319 die Ausbildung der charakteristisch-hebr. Verwendung von wa-Perf.

326 Dazu ausführlich Smith, Origins, 35 ff., speziell die Zusammenfassung 59-63; vgl. ders., »The Waw-Consecutive at Qumran, « ZAH 4 (1991): 161-164. Auch hier ist selbstverständlich mit der gleichzeitigen Existenz verschiedener Sprachsysteme zu rechnen, nicht einfach der vollständigen historischen Ablösung des einen Systems durch das folgende (ebd. 62f.). - Auch in der alttestamentlichen Exegese wurde immer wieder darauf hingewiesen, dass auch in späten Texten der Bibel neben einzelnen Fällen von narrativem wa-Perf. die klassische Verwendung von Perf. cons. und Narrativ deutlich überwiegt (Spieckermann, Juda, 128; Koch, »Gefüge«: 83; 87; Pietsch, »Tempus«: $164 \mathrm{f}$.; die Zahl der Texte, die manchmal für ein narratives $w a$-Perf. in Anspruch genommen werden, ist ggf. nochmals zu verringern [ders., „Ein Aramaismus im spätbiblischen Hebräisch?, « in Sieben Augen auf einem Stein (Sach 3,9). Festschrift für Ina Willi-Plein zum 65. Geburtstag, Hg. Friedhelm Hartenstein und Michael Pietsch (Neukirchen-Vluyn: Neukirchener, 2007): 286-307]). 
renden aramäischen Königsinschriften lassen dieselbe Sprache vermuten, wo es sich um militärische Erfolgsnachrichten handelt. In kaum einem antiken Lebensbereich wären Fehlinterpretationen durch den Rezipienten - gerade im Blick auf Tempus und Modus - derart fatal und mit tödlichen Folgen verbunden gewesen. Die scheinbare Mehrfachfunktion der Tempora, das Nebeneinander von wa-Perf. in nachzeitigem Sinne (Bedingungssatz, finale Folge von volitiven Modi etc.) und historisch-vorzeitigem wa-Perf. (ggf. zudem wa-Kurz-Ipf.) müssen also durch ihren Kontext, die Phraseologie usw. so klar definiert gewesen sein, dass Fehlinterpretationen auszuschließen waren - auch über größere Distanzen hinweg und unter Personen unterschiedlicher Herkunft, wie bei den kanaanäischen Amarnabriefen und deren Absender bzw. Empfänger in Ägypten. Dass im Einzelnen auf die Zeitlage eindeutig definierende Adverbien oder Partikel verzichtet wurde, ${ }^{327}$ macht deutlich, dass das Tempusmorphem im Zusammenhang mit Redetypus, Satzstellung und Konjunktion als eindeutig empfunden wurde.

\subsection{Sprachgattungen - Sprachebenen}

Man muss zudem wenigstens mit drei nebeneinander existierenden Sprach- bzw. Literaturgattungen rechnen: a) die literarische Prosa, wie sie die moabitische Meša'-Inschrift repräsentiert, b) das altertümliche System von Personennamen und Teilen der hebräischen Poesie und c) das System der nichtliterarischen Alltagstexte, wie sie die meisten Inschriften belegen.

a) Literarische Prosa wie die Meša'-Inschrift kennt die dem biblisch-hebräischen Narrativ entsprechende Abfolge von wa-Kurz-Imperfekta als Gerüst der Erzählung, das dann untergliedert werden kann - aber nicht muss - durch vorzeitiges wa-x-qatal zur Kennzeichnung eines Neueinsatzes. Die ebenfalls literarische Siloah-Inschrift kennt dagegen dergleichen nicht.

b) Die Verwaltungsprosa der Briefe und Urkunden - einschließlich bestimmter konstatierender Teile z. B. der Meša'-Inschrift - kennt dagegen den Narrativ nur in spärlicher Verwendung, auf der anderen Seite - genau dem Ugaritischen entsprechend - ein dominantes Perfekt zur Darstellung vorzeitiger Sachverhalte - meist in der Form wa-x-qatal. Nicht verwundern sollte es daher, wenn gerade hier auch noch Perfekta mit $w^{e}$-copulativum auftauchen, die dem älteren ugaritisch oder Amarna-kanaanäisch belegten System entsprechen, in der Literatursprache des klassischen Hebräisch aber als ungewöhnlich erscheinen mögen.

c) Immer im Blickfeld bleiben muss die Tatsache, dass die überlieferte Poesie und besonders die Personennamen weiterhin ein System mit präteritalem KurzImperfekt - auch ohne wa- - neben der Verwendung des Perfekts und damit das altüberlieferte System der ausgehenden Bronzezeit kennen. Da als Namen mit

327 Dazu oben zum Amarna-Kanaanäischen Kap. 2.1.2.4 Abschn. 1. 
Kurz-Imperfekt als verbalem Element auch Jahwenamen nachweisbar sind, ist diese Namengattung - obwohl bereits von Martin Noth zu Recht als der spätere Namenstypus eingestuft ${ }^{328}$ - auch noch zur Zeit der hebräischen Inschriften bis zum Exil produktiv, das Tempus war also verstanden worden.

Berücksichtigt man den Unterschied von Poesie, Literaturprosa und Verwaltungs- bzw. Alltagsprosa, so mag man bei biblischen Prosa-Texten, die überwiegend dem System der literarischen Prosa entsprechen, nicht ganz ausschließen, dass sich darin eingesprengt Texte befinden, die der Verwaltungsprosa ähneln und damit ein abweichendes, besonders im Blick auf die Verwendung des Perfekts weniger festgelegtes System aufweisen - wie die Siloah-Inschrift zeigt, nicht nur in reinen Verwaltungstexten, sondern auch in Texten aus dem Bereich Chronik, Hofberichterstattung, einfacher Annalen, Berichten usw. ${ }^{329}$ Vergleichbares ist ja bereits im Ugaritischen durchaus geläufig. ${ }^{330}$

\subsection{Schluss}

Die Berücksichtigung von Aspekt - Tempus - Modus, sowie die Unterscheidung von Sachverhalten, Sprechhaltungen oder Literaturgattungen, die Analyse von Kontur und Reliefgebung (Vorder- oder Hintergrund), die Feststellung von Hauptund Nebenfunktion der Tempora sind keine Notlösungen, die nur solange notwendig sind, als man noch nicht alle Belege widerspruchsfrei in einem Gesamtsystem verorten kann, sondern sie sind das historisch eigentlich zu Erwartende.

Wenn überhaupt ein Ergebnis dieser schlaglichtartigen Bemerkungen vorgetragen werden soll, so allenfalls die Selbstmahnung, die Sprachgeschichte nicht von der allgemeinen Kulturgeschichte abzukoppeln, einer Geschichte, die keine geschlossenen Systeme und auch keine einlinigen historischen Stemmata, keine monokausalen Erklärungen kennt, sondern im Grunde nur - gar nicht mehr als solche zu bezeichnende - Übergangsstadien erwarten lässt - mit Vorgeschichte, Innovation und kontemporärer gegenseitiger Beeinflussung. Das Nebeneinander verschiedener Personengruppen unterschiedlicher Herkunft einerseits und

328 Vgl. die Namenbeispiele bei Martin Noth, Die israelitischen Personennamen im Rahmen der gemeinsemitischen Namengebung, BWANT III 10 (Stuttgart: Kohlhammer, 1928), 28; 244-248 und besonders Ran Zadok, The Pre-hellenistic Israelite Anthroponymy and Prosopography (Leuven: Peeters, 1988), 35-42.

329 Bereits Meyer, »Erzählungsstil«: 123 vermutete - unter anderen Vorbedingungen -, dass die wa-Perfekta in II Reg 18,3 f. und 23,4 ff. einer »Benutzung von Annalen oder annalistischer Literatur" geschuldet sind.

330 Dazu oben Kap. 2.1.1. 
verschiedener Redesituationen andererseits lässt im Grunde gar nichts anderes erwarten.

Wenn sich die Zeit der hebräischen Inschriften nicht als fertiges geschlossenes System darstellt, so ist dies insofern auffällig, als diese Zeit gleichzeitig die der noch im Alltag gesprochenen und geschriebenen hebräischen Sprache ist, während das Sprachsystem möglicherweise für einen gewissen, relativ langen Zeitraum umso geschlossener wirkt, je mehr das Hebräische als Verwaltungsund dann auch Umgangssprache zurücktritt - um dann am Ende dem parallel schon vorher entstehenden, in sich selbstverständlich wieder ausdifferenzierten, als mittelhebräisch bezeichneten System weichen zu müssen.

Zusammenfassung: Untersucht wird das Auftreten der Abfolge wa-Perfekt / AK (Konjunktion wa- mit unmittelbar folgendem Perfekt), die in literarischer Prosa des Klassisch-Biblisch-Hebräischen als Perfectum consecutivum und damit funktionsidentisch (im Sinne einer Alloform) mit Lang-Imperfekt und vergleichbaren imperfektiven Konstruktionen erlaubt wäre. Dabei zeigen mehrere inschriftlichhebräische Belege, dass in manchen Fällen wa-Perfekt für eindeutig perfektivvorzeitige Sachverhalte verwendet wird, allerdings ausdrücklich nicht im Sinne eines Narrativs (wa-Kurz-Imperfekt), der innerhalb der althebräischen Inschriften ausgeprägte Progressfunktion aufweist. Die Verwendung von wa-Perfekt wird dabei in den Kontext vergleichbarer Konstruktionen im Ugaritischen, AmarnaKanaanäischen sowie in mit dem Althebräischen kontemporären phönizischen und aramäischen Inschriften gestellt. Hier macht das Nebeneinander von waPerfekt zur Darstellung vergangener Sachverhalte sowie im Nachsatz von Bedingungssätzen für tendenziell Nachzeitiges in den außerhebräischen Sprachen wie auch im außerbiblischen Hebräisch jeweils im selben Textcorpus deutlich, dass Sprachökonomie in der Form, dass eine eindeutige Korrelation von Morphemtyp und Tempusfunktion notwendig sei, offenbar keine Rolle spielt. Insgesamt wird nochmals unterstrichen, dass für die Wahl des morphologischen Tempus (einschließlich Konjunktion und Satzposition) nicht nur Aspekt, Tempus (einschließlich Progress oder Regress) und Modus eine Rolle spielen, sondern speziell auch Reliefgebung, Beginn oder Abschluss einer Sequenz, Stilistik und speziell auch die Sprachgattung: Poesie, literarische Prosa, Verwaltungsprosa.

Summary: This paper discusses the usage of the sequence wa-perfect (conjunction wa-immediately followed by perfect / suffix conjugation) in Ancient Hebrew. While in biblical literary prose this »tense « is understood in the classical system as consecutive perfect - functionally identical (as allomorph) to imperfect (long form: yaqtulu) and other imperfective constructions - in Epigraphic Hebrew there 
are some cases where $w a$-perfect has to be understood as perfective and past time tense. This result is consistent with the fact that in Pre-Hebrew Canaanite as in contemporary Phoenician and Aramaic wa-perfect is simultaneously used for past time narratives as also for the apodosis of conditional sentences with inherent future meaning - often in the same corpus. Nevertheless wa-perfect is never functionally identical with Hebrew wayyiqtol which in Epigraphic Hebrew clearly denotes progress. The usage of wa-perfect and other tenses in the North-WestSemitic languages including Epigraphic Hebrew shows the well known fact that the decision for a specific tense is determined not only by aspect, time (including progress or regress), and mood etc., but especially also to denote highlighting (foreground and background), the beginning or ending of a sequence, to realize special stylistic features and after all by the type of the literature: poetry, literary prose or administrative prose.

Résumé: Cet article traite de l'usage de la séquence wa-accompli en hébreu ancien. Dans la prose littéraire de l'hébreu biblique classique, ce «temps» est traditionnellement compris comme un accompli consécutif, identique (comme allomorphe) à l'imparfait. Cependant plusieurs inscriptions hébraïques ainsi que les langues nordouest sémitiques attestent du wa-accompli comme un accompli et un temps passé. Cela démontre avec évidence le fait bien connu de l'impossibilité d'établir une corrélation entre un type morphologique et une fonction temporelle. Le choix d'un temps morphologique n'est pas seulement déterminé par l'aspect, le temps et le mode, mais aussi l'emphase, le début ou la fin d'une séquence, des considérations stylistiques et également le genre de littérature: poésie, proses littéraire et administrative. 